\title{
GLADIOTRON - 3D INTERACTIVE COMICS AS AN IDEAL ENTRY POINT FOR TRANSMEDIA IP DEVELOPMENT
}

by

\author{
Gavin Ronald Nelson Ball, \\ Animation Arts Advanced Diploma, Seneca College, 2006
}

A Major Research Paper

presented to Ryerson University

in partial fulfillment of the

requirements for the degree of

Master of Digital Media

in the program of

Digital Media

Toronto, Ontario, Canada, 2019

(C) Gavin Ronald Nelson Ball, 2019 


\section{AUTHOR'S DECLARATION FOR ELECTRONIC SUBMISSION OF A MRP}

I hereby declare that I am the sole author of this MRP. This is a true copy of the MRP, including any required final revisions.

I authorize Ryerson University to lend this MRP to other institutions or individuals for the purpose of scholarly research.

I further authorize Ryerson University to reproduce the MRP by photocopying or by other means, in total or in part, at the request of other institutions or individuals for the purpose of scholarly research.

I understand that my MRP may be made electronically available to the public.

Gavin Ronald Nelson Ball

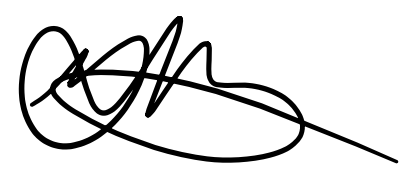




\section{Abstract}

Gladiotron is an online, interactive, 3D web-comic designed to test the efficacy of leveraging assets created for a 3D comic for reuse in other forms of media around the same intellectual property (IP), in this case a game, animation, and merchandise. The Gladiotron 3D web-comic exhibited advantages over basic storyboarding by increasing speed and efficiency of production between the comic and the game, audience growth potential, and opportunities for audiences' feedback. This 3D web-comic model also demonstrates an alternative approach for developing video games and developing IPs.

Keywords: WebGL, Babylon.js, web-comic, interactive, indie game development, marketing, production 


\section{Acknowledgements}

I would like to, first and foremost, thank Ryerson University for allowing me to pursue this research paper. Also, to Ahmed Sagarwala, you helped me cross the finish line when things seemed uncertain, for which I am eternally grateful. To Dr. Michael Carter, thank you for agreeing to be my second reader; I look forward to the continued growth of the MDM program under your leadership. Thank you to Dr. Alex Ferworn for your attention to my circumstances and answering my questions which encouraged me to apply to the program. Thank you to Dr. Naimul Khan and Dr. Andrew Hogue for your support in helping me to grow as a programmer in my transition from a digital artist to an interactive-media developer.

For helping to nurture and grow my Gladiotron media project both creatively and entrepreneurially, I would like to express my gratitude to the MDM 6.0 cohort and the Transmedia Zone community for your encouragement.

For challenging me to push beyond the obvious and explore an idea that has led to this research paper, I want acknowledge Kathryn McKenzie who has helped to shape what this MRP has become as my supervisor and my strategy lead at the Transmedia Zone.

To the Gladiotron team past and present, your contributions have been instrumental in helping Gladiotron become what it is today. Special thanks to Kristian Campbell for WebGL help and Maya McMullen for managing and growing the Gladiotron community on social media.

Finally, to my parents, my wife, and my kids; none of this would be possible without your patience and support during a busy year. I appreciate you more than you know. A special thanks to my mother Yvonne Nunes for going above and beyond to help in whatever way was needed this year. 


\section{Dedication}

To the little brother I never had, I hope that the story I am creating will give you the direction I wish I had growing up. To my children, I hope that you tell your own stories one day. To all the little boys and girls who have ever felt like they didn't belong, were less important, or didn't see the point, this is for you. 


\section{Table of Contents}

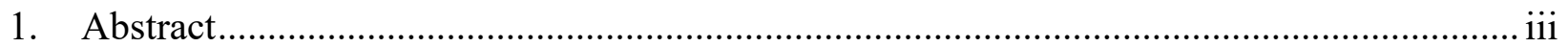

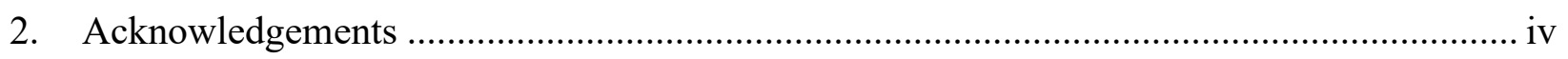

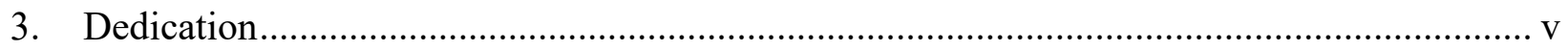

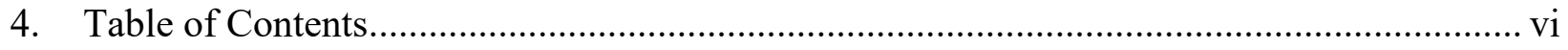

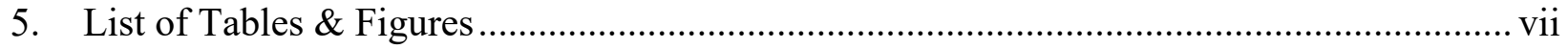

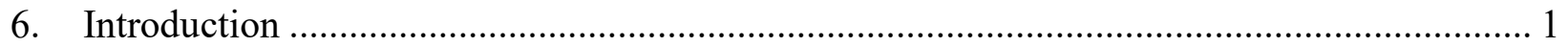

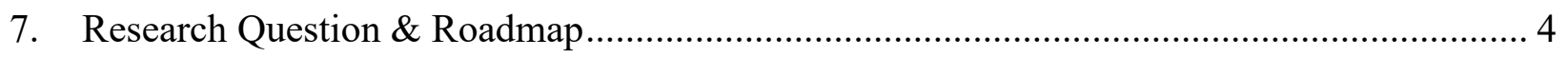

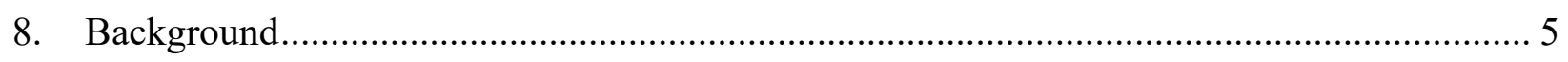

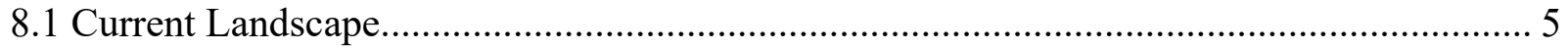

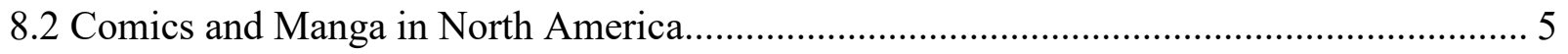

8.3 Risks Associated with IP Development ................................................................ 6

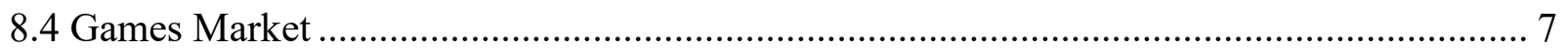

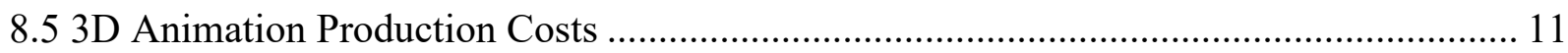

9. Conceptual Framework \& Literature Review .................................................................. 12

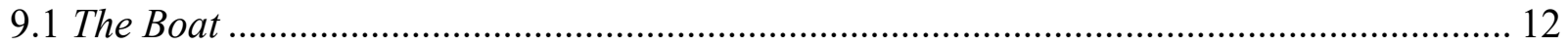

9.2 Homestuck, Undertale, and Hivestuck - Online Comic to Kickstarter Success ............... 13

9.3 Transmedia Manhwa in Korea, Manga in Japan, and Webtoons in North America.......... 16

9.4 Real-time Rendering for Animation Production Using Game Engines ........................... 20

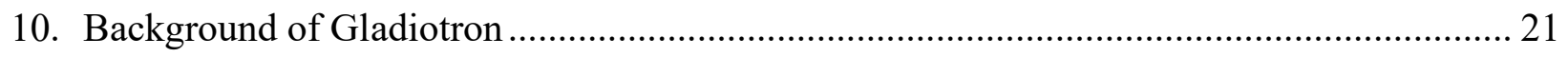

10.1 Overall Project Scope and Intermediate Goals ......................................................... 21

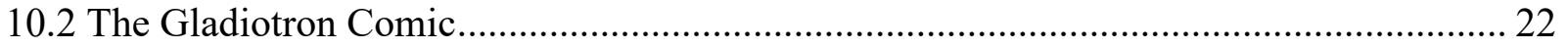

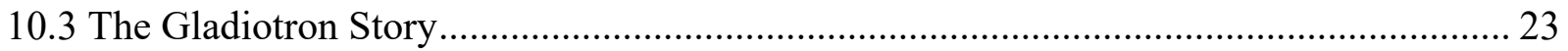

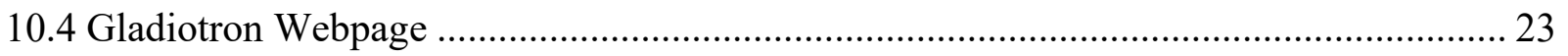

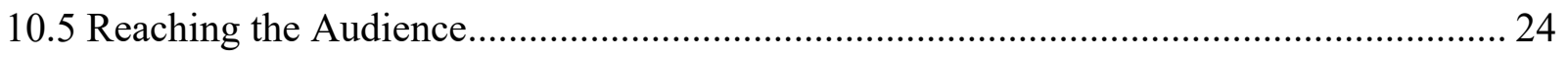

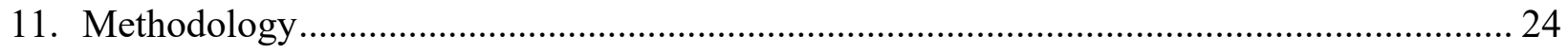

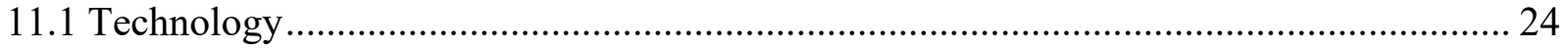

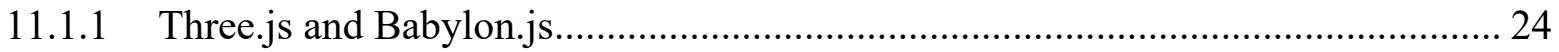

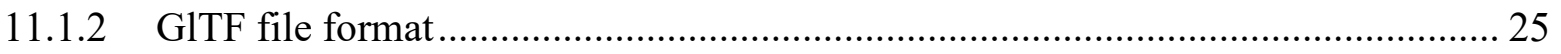

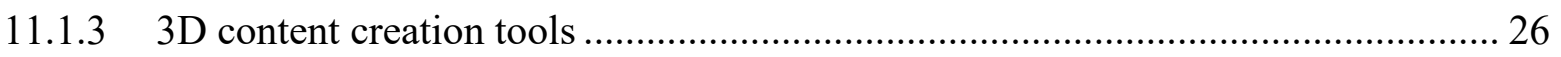

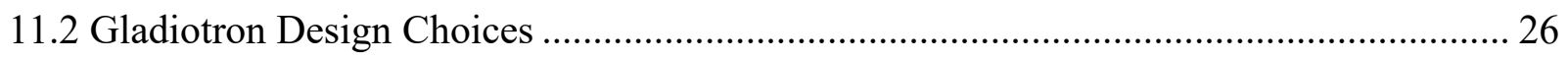




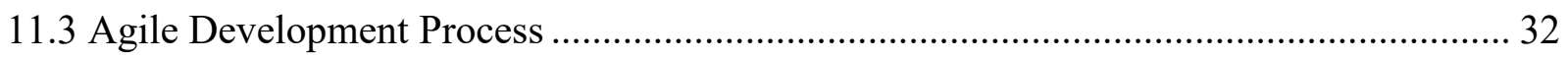

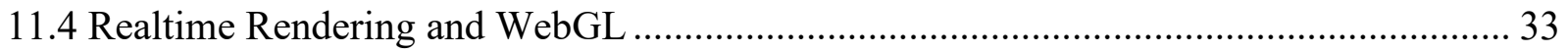

12. Product Described \& Design Strategy Explained............................................................... 35

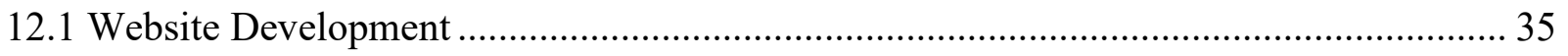

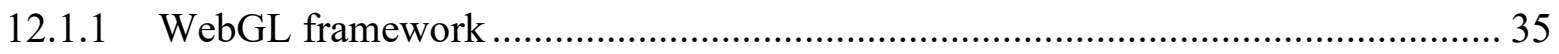

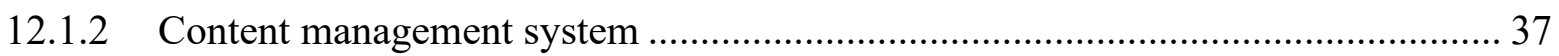

12.1.3 Integrating Babylon.js with Processwire .............................................................. 37

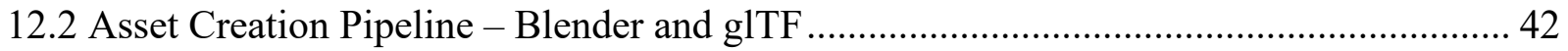

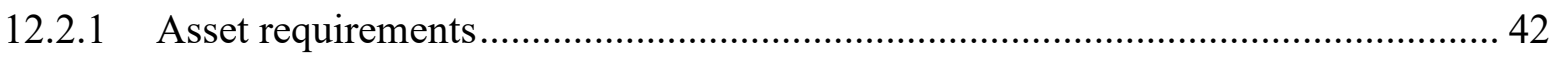

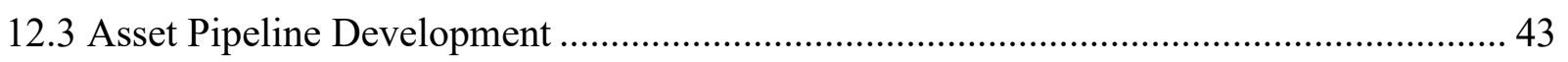

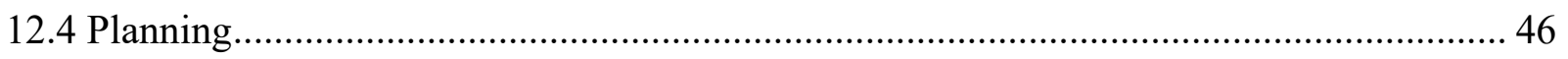

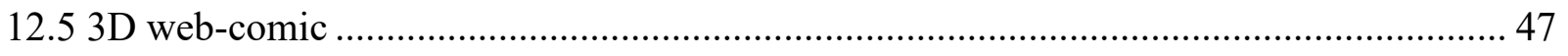

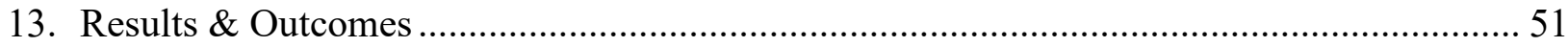

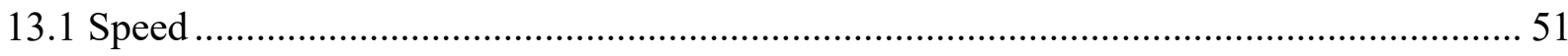

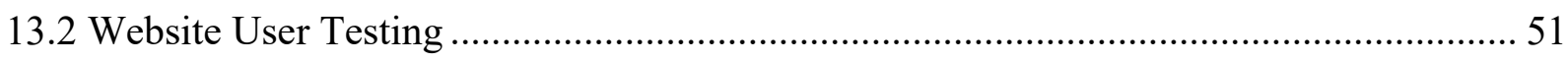

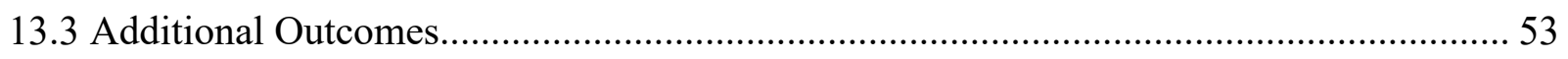

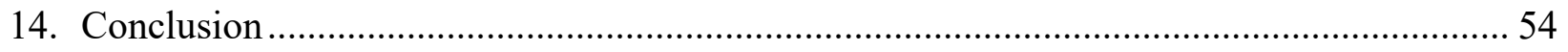

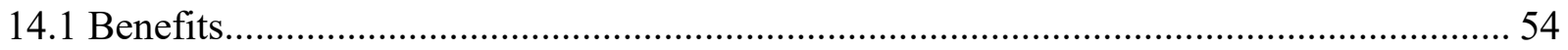

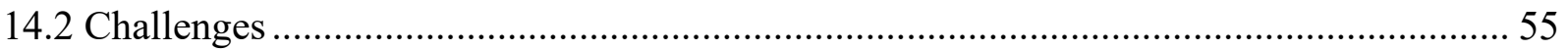

15. Contribution to Professional Practice ................................................................................ 55

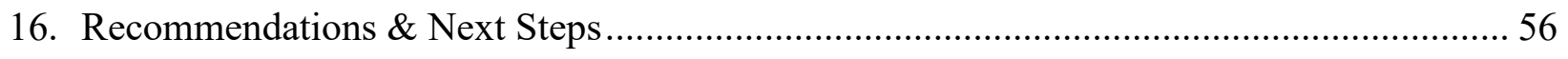

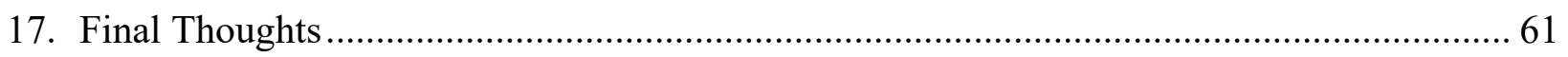

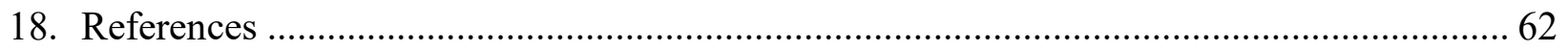

\section{List of Tables \& Figures}

Figure 1 - Sketchfab artwork that blurs the lines between 2D and 3D art (Abad, 2018) ......................... 2

Figure 2- Manga and comic sales in the US at bookstores and department stores (NPD, 2019)............... 6

Figure 3 - Respondents to the question "Why did your indie game fail?" on Quora (Quora, n.d.) ...........9

Figure 4 - Post from Outerloop Games’ social media (Francis, 2019.) …............................................... 10

Figure 5 - costs of creating animated content produce (Get Wright On It, 2017) ................................... 11

Figure 6 - showing an aside section to the main narrative in The Boat (SBS, Le, \& Huynh, 2015).......... 12 


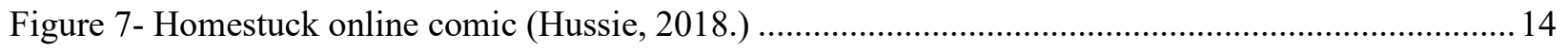

Figure 8 - manhwa Reid from comic.naver.com (Eui-chul \& Hyun, 2019)........................................... 17

Figure 9 - Difference between Gladiotron proposed pipeline and traditional transmedia pipelines........... 19

Figure 10 - Still image from the show Zafari (Zafari Holdings \& BE3 Animation, 2018) ...................... 20

Figure 11- Images posted to social media can be also be sold as merchandise ........................................ 31

Figure 12 - Gladiotron main character, Commander Bean, being prepared for 3D printing ....................31

Figure 13 - Sketchfab monthly pricing in USD (Kickstarter, n.d.) ........................................................ 36

Figure 14 - Showing PHP and JavaScript code in Hanna Code module in Processwire CMS.................. 40

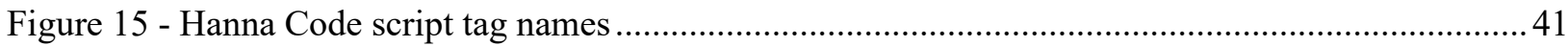

Figure 16 - Hanna Code tag embedded into the field of one of the sites pages ....................................... 41

Figure 17 - Non correspondence of Blender rig and animation and glb export...................................... 44

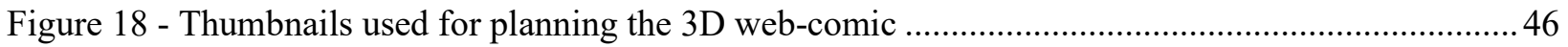

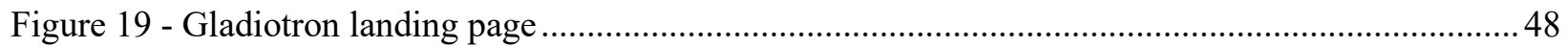

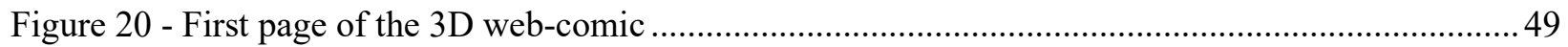

Figure 21 - Scene from one of the panels shown in Blender ................................................................50

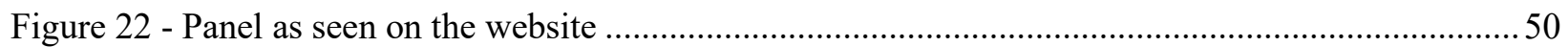

Figure 23 - Main playable characters for Gladiotron (currently in various stages of development) ..........58

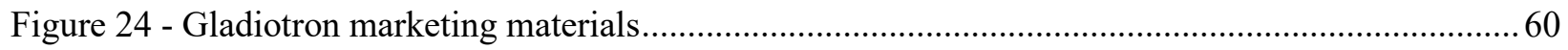

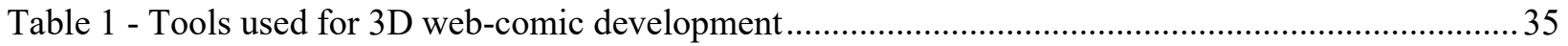




\section{Introduction}

As an interactive media developer who grew up an avid fan of video games and comic books, it only seems natural that I would seek opportunities to combine the two forms of media in my own work. Gladiotron is a project that takes the familiar aspects from these two forms of media and creates something new. From the perspective of using a web browser as a digital canvas, I decided to take advantage of recent developments in web and graphics processing technology to create something that would not be possible in a traditional comic book. With a

focus on the comic book format, I wanted to explore the possibilities presented by the medium of the web to create an interactive, 3D, audio-visual experience that would be more dynamic and immersive than a standard comic. The goal was to push the boundaries of comic creation in a way that still allows the final product to feel like a comic, while presenting as a unique and novel experience that would not be possible in a standard print or $2 \mathrm{D}$, image based online comic. The web presents a plethora of possibilities ranging from the ability to embed images, create interaction events, add audio and video, and most recently (and most importantly), create 3D scenes.

With Gladiotron being a self published original transmedia project with a planned game and episodic animated series based on the same intellectual property (IP), it made sense to look for ways in which I could also build an audience for the project. Two strategies were considered initially to market the game. One being social media progress updates and the other was an online web-comic designed to cultivate an audience over time. Exploring the comic idea further, it made sense to make it available online and for free in order to remove any potential barriers for audience adoption. It was also a goal to find ways to leverage elements made for the game in the comic and visa versa in order to maximize the investment of time required to make the comic. 
During this time, I stumbled across an online art piece on the 3D art website called Sketchfab where an artist found an interesting way of blurring the line between a flat graphic image and a 3D scene (Figure 1) (Abad, 2018). The scene contained a white framed window into what looked like a painting. Upon clicking and dragging on the 3D art piece, it was apparent that there was a depth and the frame was more like a window into a little scene. I appreciated this innovative and unique approach to art. It felt both 2D and 3D at the same time. Since the image was in fact 3D and the user was able to change the view, it allowed the viewer to peek deeper into what felt like an illustration and see more than what was immediately apparent (Abad, 2018).
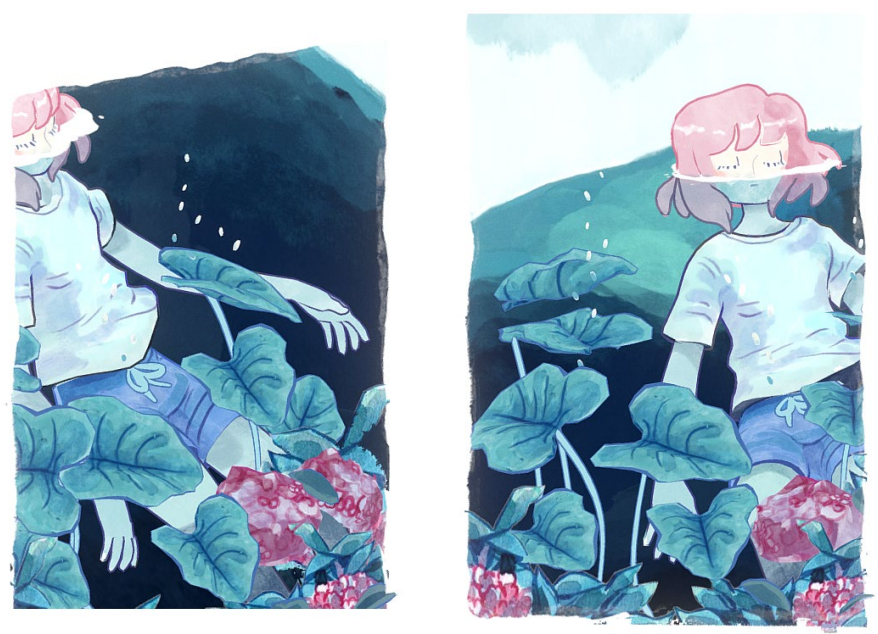

Figure 1 -Sketchfab artwork that blurs the lines between 2D and 3D art (Abad, 2018)

After some thinking, the idea to create an online comic which would include a series of 3D windows set in the browser to appear like a comic book page began to emerge. The hope was that upon first impression, a user would perceive that it was a regular flat comic made up of graphic images, but then reveal through animated cameras, and characters that each panel was in fact a living breathing 3D scene that could be explored and in some cases interacted with like a 
game. This approach would solve several problems that applied to our transmedia project. For example; how to convert an audience for a comic into an audience for a game? While there might be some overlap between comic readers and gamers, it is not something that could be assumed. By blurring the line between comics and games, it could be theorized that people who enjoy the Gladiotron interactive web-comic would be more likely to appreciate the actual game. Also, could the comic be used to gain insights from user feedback to better adjust the development of the overall IP? Releasing a comic through periodic updates would provide an ideal opportunity to obtain user feedback and course correct the project along the way. This feedback would then provide us with actionable insights into what to focus on in regards to the comic and the game. Another key benefit would be the ability to reuse 3D models, music, and animations made for the comic in the game. This was very important, because as a small team, making a regular comic would have slowed progress on the development of the game. By making the comic 3D, it would allow work on the comic to directly contribute toward the development of the game as well. Finally, and perhaps most importantly; the comic would quickly demonstrate the viability of the IP. We would be able to find out whether or not audiences were responding positively, whether or not we were reaching our intended audiences, and whether or not we were having the desired effect before investing time and resources into something bigger.

On a personal level, making things this way would also provide me with a vehicle to explore interactive art, with the web page as my canvas in a way that would allow me to better develop my design, modeling, animation, programming, and music composition skills. 


\section{Research Question \& Roadmap}

This paper examines the process of introducing non-mainstream transmedia IP to audiences through interactive, online, 3D web-comics. It will test the efficacy of leveraging assets created for a 3D web-comic for reuse in other forms of media using the same IP.

This research is primarily for the benefit of indie game developers, but also for service-based game and/or animation studios who are aiming to get their IP media projects to market while retaining ownership and creative control in a lower risk, less resource intensive way. The additional benefits of this process relate to finding the desired target audience, growing said audience, and deploying content informed by that audience's feedback over time.

The process proposed above has been explored during the development of a serialized 3D interactive comic for a transmedia project called Gladiotron, a video game being developed in addition to the interactive 3D web-comic

This paper explores whether it is possible to streamline the process of transitioning from comic to game to animated production while staying nimble enough to respond to audience feedback along the way. It will also determine whether a 3D web-comic provides advantages over basic storyboarding particularly in the areas of increasing speed and efficiency of production between the comic and the game, audience growth potential, and opportunities for audience feedback. 


\section{Background}

\subsection{Current Landscape}

The current state of games and comics will be touched on in addition to the production costs of games, animated films, and animated shows. Current production methods that leverage the use of game engines will be explored and comparable projects will be reviewed to highlight similarities and differences with the Gladiotron project discussed in this paper.

\subsection{Comics and Manga in North America}

Comics have seen a recent uptick in popularity in North America (Figure 2) with growing popularity amongst teens and young adults of graphic novels and manga, which correlates to transmedia adoption of animation, merchandise, and games (NPD, 2017) as shown by NDP Group's market research:

Manga, a graphic form native to Japan, is a particularly strong area of growth for both adolescents and adults. Manga is skewing the youngest of all of the comics and graphic novels categories, with 76 percent of the purchasing being done by those ages 13-29. Manga buyers are also the most diverse group of buyers of comics and graphic novels; they are 20 percent less likely to be white than the overall population of comics and graphic novels buyers.

"There is a whole new audience emerging for comics and graphic novels; these readers are younger, they are more diverse, and they are getting their books from a much wider range of channels than we typically think of for comics," said Kristen McLean, industry analyst for NPD Books. "This is also a very interesting category when it comes to 
crossover and media tie-ins from across entertainment, including film, toys, and gaming.

We have seen this category grow for a few years now, and we have no reason to think it's just a flash in the pan.” (NPD, 2017)

This shows that manga and comics are a proven vehicle for initiating transmedia content that spans games, animations and toys.

\section{Manga Monthly Unit Sales}

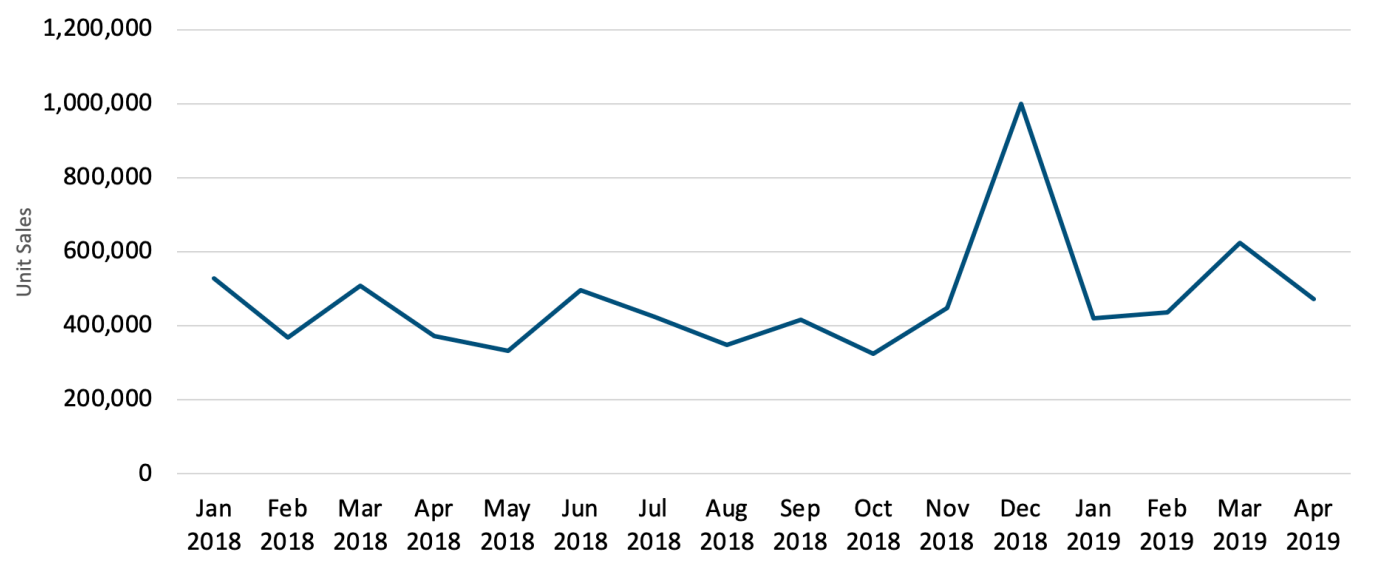

Source: The NPD Group/NPD BookScan

\section{(๑) The NPD Group, Inc. , 2019.}

Figure 2- Manga and comic sales in the US at bookstores and department stores (NPD, 2019)

\subsection{Risks Associated with IP Development}

IP development is a risky, time consuming venture and in the case of games and animation, it can often be very expensive (Get Wright On It, 2017) (Superannuation, 2014). If your project does get produced, it needs to be good, but that is only half the battle because people 
must also find out that your project exists, or there will be no one to support it (Bestebroer, 2017). This is especially the case with new, unproven genres. Even Disney has moved out of the game development business due to the risks associated with new IPs. It has instead moved to a licensing model where they license their properties to external game development studios as a safer strategy (Gilbert, 2016).

\subsection{Games Market}

The game industry in the US continues to enjoy sustained growth and is projected to continue growing at an annualized rate of $3.8 \%$ to 24.4 billion dollars from 2018 to 2023 on top of realized growth of $6.6 \%$ from 2013 to 2018 including a one year jump in 2018 of $5.5 \%$ to 20.2 billion dollars (Diehl, 2018) this coincides with a large increase in independent developers and lower barrier to entry due to digital marketplaces, such as Steam and Apple's App Store (Diehl, 2018).

Heidi Diehl (2018) further reports that:

The dominance of large publishers in this industry has not prevented enterprise growth over the past five years. As new, smaller companies become successful, major players usually acquire them to expand their customer bases and market share. Additionally, the rise of smartphones has led to an explosion of independent game developers. (Diehl, 2018)

Lower barriers to entry and increased game offerings have also had the effect of making a competitive marketplace even more competitive (Diehl, 2018). 
Independent developers generally own their game intellectual property (IP) outright when they go to market, so when a game is a hit, they benefit directly from the proceeds, as was the case for Flappy Bird, which purportedly made it's developer up to $\$ 50,000$ per day through ad revenues (Terdiman, 2014). However, for every Flappy Bird success story there are countless games that make little to no impact before fading away into obscurity.

On top of this challenge, indie game developers often face obstacles that larger publishers do not, such as limited access to production funds or a lack of skills or resources to complete large scale projects with high quality (Bestebroer, 2017).

In fact, multiple indie game developers responded to the question 'Why did your indie game fail?' on Quora with answers that are all too familiar with independent developers. There were a few common responses such as insufficient marketing prior to the launch of the game; not being able to make prompt adjustments based on user feedback; and limited resources (i.e, time, money and/or manpower) with which to move quickly (Quora, n.d.) (Figure 3). 
Quora 国 Home $\Gamma$ Answer \&ol

Jason Huskie, Game Developer for 7 years and Gamer for 32 years

Updated Apr 30, 2017 - Upvoted by Mark Maratea, Client Architect - Gameplay

Because of me. Any other answer is inadequate.

The list of precise reasons is below:

1. wrong staff

2. not enough money. I spent $\$ 100 \mathrm{k}$ but needed $\$ 300 \mathrm{k}$ at least

3. I wasn't assertive enough when people didn't deliver my specifications. I tried to stay friends with employees and make everyone feel valued. The game suffered as a result.

4. $\mathrm{i}$ listened to fans. Real fans will mislead you as much as the haters who come later will mislead you. Stay true to your vision and use player suggestions when they slim with your vision

5. the market became a flooded mess of garbage about 11 months after we launched. We had a good first year and expected more of the same. Unfortunately the players became fatigued, angry, confused and yes a little spoiled. A lot of games better than mine failed due to lack of exposure or jerks damaging perception of studios or games unjustly.

6. I didn't respond quickly enough. I saw the writing on the wall 5 months before we were in trouble. I even warned my consulting clients about the issues. Unfortunately I overestimated everything good and underestimated everything bad.

Eventually you you have to pull the plug on a bad game. Wait to long and you can't make another, better game. I don't enjoy the forum interactions on Steam anymore so I stopped making games professionally. I still consult on a bunch each year and I'm working on a free remake of my game for real fans in my free time.

I would be VERY hesitant to go back to making games full time again. The climate is so far from what people remember from the indie boom of 2011 that it's not even funny. The new devs are mostly delusional to some degree and woefully unprepared in most cases. That's why the failure rate went from 7/10 in 2011(within 12 months of

仓 Upvote 261 G Share $B d \infty$

Figure 3 -Respondents to the question "Why did your indie game fail?" on Quora (Quora, n.d.)

Large budget videogames, also called AAA games, often have production budgets in excess of \$50 million USD (Superannuation, 2014). This does not include marketing which has become more important than ever:

In 2009, EA executive Rich Hilleman indicated in a speech that his company "now typically spends two or three times as much on marketing and advertising as it does on developing a game." This formula is not necessarily applicable to every potential 
blockbuster game — a "AAA game", in gaming parlance — or to every company, but it is fair to say the break-even point for the average AAA game is well above the development budget. (Superannuation, n.d.)

Marketing is obviously a very important component of any video game, even more so for indie developers who do not have nearly the same budgets or visibility as large game producers. Which is why indie developers often use social media for marketing because it is free, and it can start generating interest prior to the game's release (Francis, 2019). Developer Outerloop Games has had success in this regard by using social media to generate interest in their game Falcon Age by posting a variety of images to Twitter and seeing which posts people responded to the most, which in turn factored into their development choices. One of their most popular posts dated February 10, 2019 received 110,000 plays, over 8,000 thousand likes and over 2,000 comments (Figure 4) and helped them gain a better understanding of what their audience was looking for (Francis, 2019).

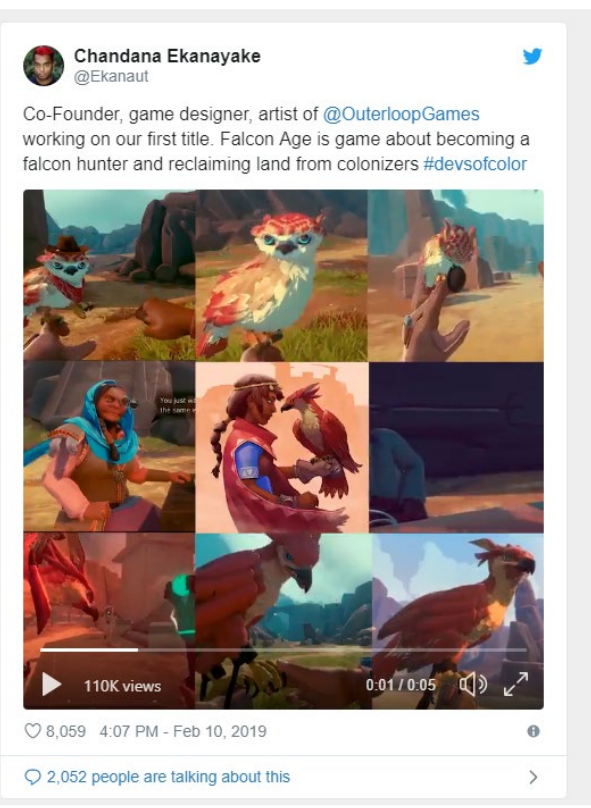

Figure 4 - Post from Outerloop Games' social media (Francis, 2019.) 


\subsection{D Animation Production Costs}

3D Animation is a time intensive, expensive process. The cost to produce a 22-minute 3D animated show is approximately $\$ 263,000$ USD (Figure 5) and a 13-episode season would cost in excess of $\$ 3.4$ million. Even more expensive, an animated feature film in the Pixar/Disney style, would cost in excess of $\$ 70$ million USD (Figure 5) to produce (Get Wright On It, 2017).

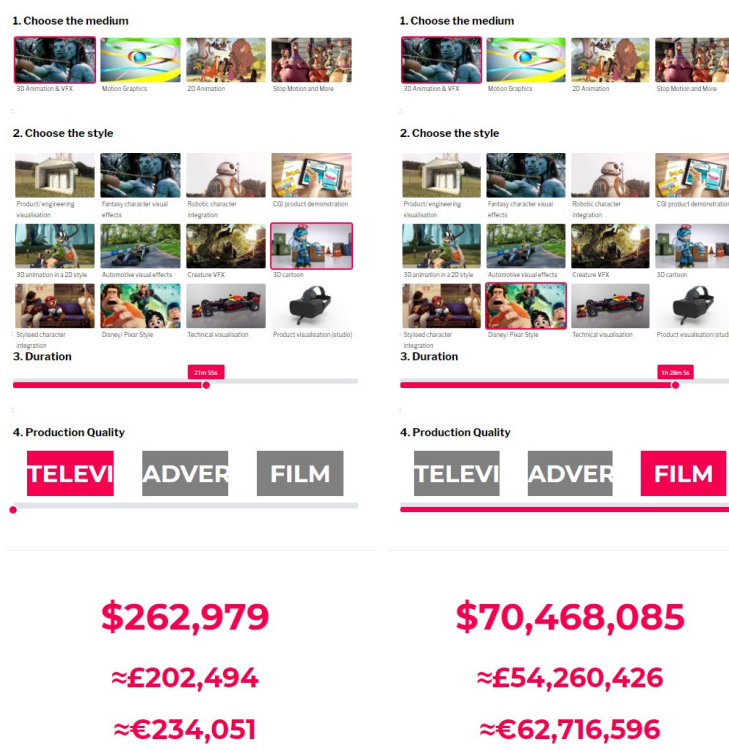

Figure 5 - costs of creating animated content produce (Get Wright On It, 2017)

These figures do not include voice acting and marketing, so the total price tag could be significantly higher. Due to the cost, animation production is a risky investment, as there is no guarantee the project will be profitable. Just like big budget AAA games, producers and publishers have become increasingly reliant on sure bets and are less likely to take a chance on unproven ideas that do not have a well-defined target audience (Gilbert, 2016). This has led to a preference for producing sequels to successful projects in both animated feature films and AAA games (Gilbert, 2016). When new IPs are made, companies will invest money into market 
research and focus testing before they get greenlit (Nielsen, 2016) to reduce the risk as much as possible, but there is still a cost associated. And in the case where studios will create a pilot animation for more extensive testing, the cost is still \$263,000 USD for one 22-minute pilot episode.

\section{Conceptual Framework \& Literature Review}

\subsection{The Boat}

Through the course of this research, various WebGL projects were looked at to find something similar to the Gladiotron proposal. There were many interesting examples, but the closest to this concept was The Boat produced by SBS and adapted from the book by Nam Le (SBS, Le, \& Huynh, 2015).

The Boat is an award winning interactive graphic novel and is an example of a web-based comic that uses $3 \mathrm{D}$ technology. It is an audio-visual experience told in a compelling way that would not be possible as a traditional flat comic. The format consists of one long page that the user scrolls down to reveal more of the story. Visual and auditory elements on the page change as you scroll down, with clickable components that take you outside the story to provide additional background information (Figure 6).
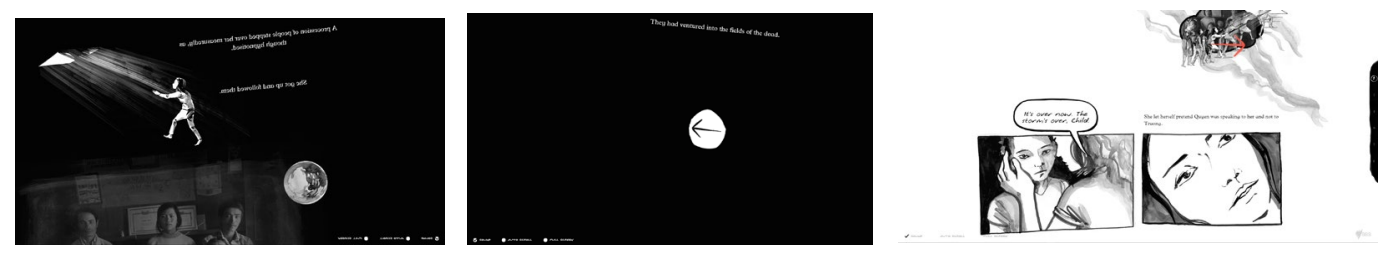

Figure 6 - showing an aside section to the main narrative in The Boat (SBS, Le, \& Huynh, 2015) 
The Boat can be considered a transmedia experience because it exists as both a book and an interactive graphic novel. The Boat serves as a good point of reference for this research since it an example of how WebGL can be used to advance the comic medium through a web browser. The Boat is also an example of a free, easily accessible experience. There is no pay wall or requirement for any extra equipment beyond an internet enabled device. There are, however, some key differences compared to what is being proposed in this paper. First, while set in a 3D engine (Three.js), The Boat features 2D artwork which does not provide the flexibility to make 3D games or animations using the same assets. Second, the comic was released in its completed state n April 2015, meaning it was not released in portions on a regular basis. This would preclude the developers from evolving the story over time with insight from their audience.

It should be stated that The Boat appears to have been released as intended with no goals for games or other forms of media based on it. As such, it has been chosen here primarily as an example of how free online comics are currently being created using WebGL technology.

\subsection{Homestuck, Undertale, and Hivestuck - Online Comic to Kickstarter Success}

Homestuck is an indie web-comic created by Andrew Hussie. It featured an innovative delivery format whereby readers could contribute to the story by answering prompts from the creator. An answer from the community would be chosen and then implemented into the next page of the comic (Figure 7). 


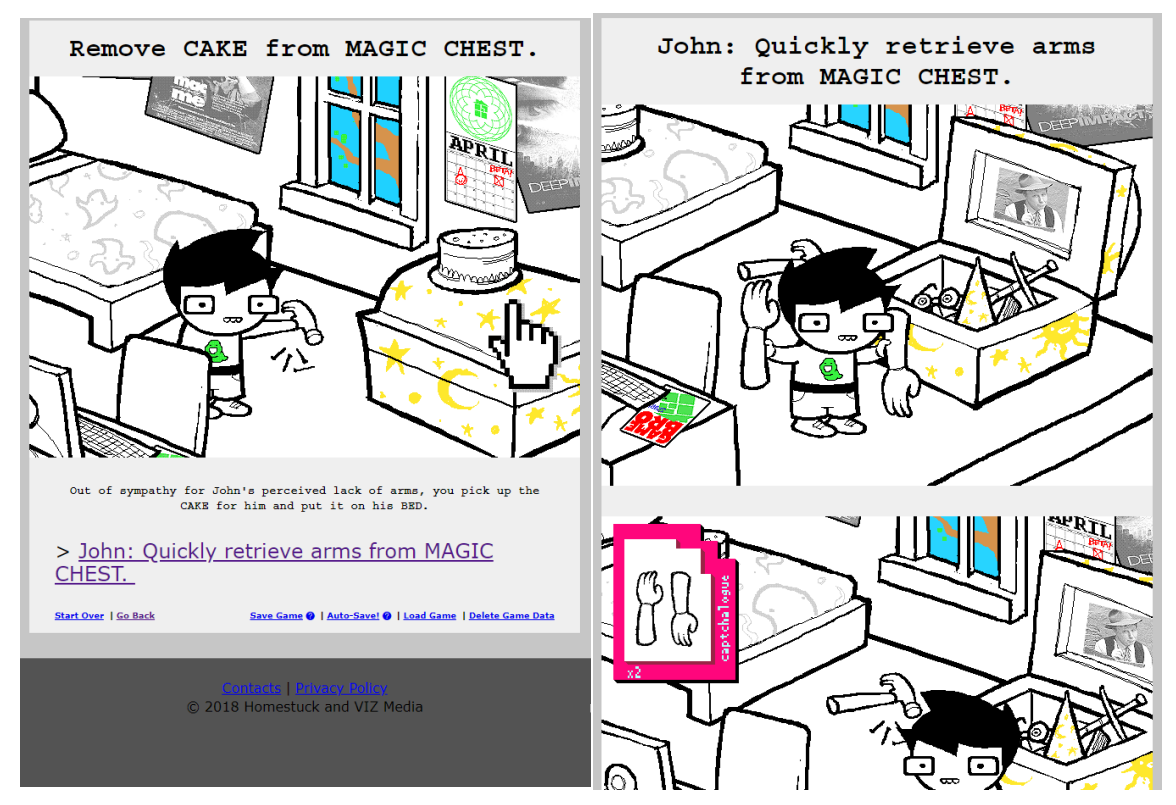

Figure 7- Homestuck online comic showing user suggestion being implemented in following panels (Hussie, 2018.)

The comic also featured animations, audio and game like portions; blurring the line between linear and interactive media. The creator was able to implement audience contributions quickly through the use of simple graphics and development support from community volunteers. The comic was also made available for free which eliminated barriers for new readers and was released as a serialized story which was able to evolve over time with audience feedback. Many of these techniques used in Homestuck are being proposed in this paper, such as; including animations; soliciting input from readers to adjust or augment the direction of the narrative; including interactive game-like portions to blur the line between comic and game; and keeping content free and releasing in portions over time. The main aspect of Gladiotion that is being handled differently is that the Gladiotron web-comic is using game ready $3 \mathrm{D}$ assets as opposed to simple, quick to produce, 2D art. 
Toby Fox, the creator of the hit indie game, Undertale, benefitted from the online following that he amassed from his involvement as a music composer for Homestuck He began working on Undertale during his involvement with Homestuck (Hussie, 2018) and began his Kickstarter campaign while wrapping up his obligations to it (Kickstarter, 2014).

The figures on the Undertale Kickstarter campaign show that out of his total backers, 226 were new and 2,172 were returning. One of the early comments on the pledge page reads "Backed as soon as I realized it was THE Toby Fox, the demo being amazing helped too. Looking forward to this one! "(Kickstarter, 2014). It seems plausible that the campaign benefited early on from the pre-existing following the creator had from his involvement in the popular Homestuck project. Undertale, the game and Homestuck, the comic are unrelated, but the popularity of Homestuck appears to have had an impact on the success of Toby Fox's Undertale Kickstarter campaign. Which in turned helped to get his Undertale game made which has since gone on to be a runaway success and has spawned a sequel called Deltarune. Undertale was chosen as an example of a game that benefited from its creator having a preexisting audience from a web-comic that helped with a crowdfunding campaign. Key differences between the development of Undertale and the development of Gladiotron are the fact that the original serialized comic was not in any way related to the game that was eventually produced. Also, the creator of Undertale wasn't the originator of the comic, he was only involved as a composer. Finally, there is no transferability of assets from one project to the other because it is not the same project with each having a different art style. In the case of Homestuck and Undertale, this doesn't appear to be a major issue because both projects feature very simple graphics that are likely quick to reproduce. 
Homestuck helped to launch another successful Kickstarter campaign. An adventure game based on Homestuck, called Hivestuck. Andrew Hussie created the Kickstarter campaign in 2012, three years after the start of Homestuck, looking to raise $\$ 700,000$ USD to produce the game. The project was fully funded within $24 \mathrm{hrs}$ (Bergen, 2017) and ended up raising close to \$2.5 million USD total (Kickstarter, 2012). However, making the game was not a smooth process in part due to the non-transferability of assets. Development on the game was not done directly by the creators of Homestuck and was initially planned as a 3D project but eventually changed to a 2D project due to issues with the first development team (Frank, 2017). Many of the issues transitioning from one form of media to another could have been avoided had assets made for the comic been designed for use in the game. This was not the case for Homestuck and Hivestuck, which resulted in a major production delays and a disgruntled fan base. Losing Andrew Hussie much of the good will generated from the comic (Bergen, 2017).

\subsection{Transmedia Manhwa in Korea, Manga in Japan, and Webtoons in North America}

In Korea there is a popular website called www.naver.com which brings together a multitude of different types of media such as episodic video, stories and manhwa, which are Korean comics (Jin, 2015). Thousands of these manhwa can be found on the Naver sub-site comic.naver.com ("Naver Webtoon”, n.d.). What makes manhwa different from traditional North American comics or manga in Japan is that they are designed first and foremost for online consumption. Therefore, standard rules and restrictions related to print media do not apply. For example, the restriction of black and white printing for cost savings in manga does not apply to manhwa, where the primary medium is digital. For this reason, many manhwa comics are 
typically in full colour, and they are not constrained to a typical comic page structure. Instead they are presented one panel after another vertically reading from top to bottom (Figure 8) (Euichul \& Hyun, 2019), which is conducive to reading on a mobile device (Jin, 2015).

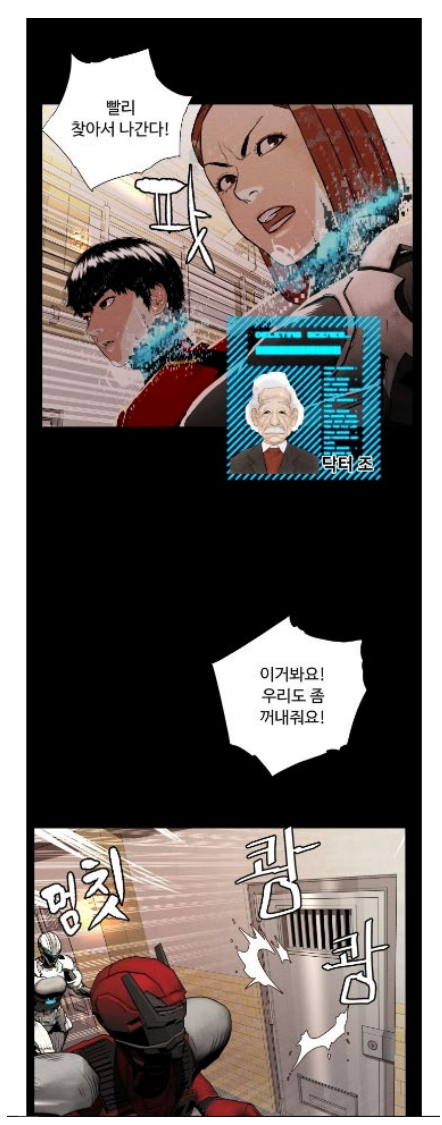

Figure 8-manhwa Reid from comic.naver.com (Eui-chul \& Hyun, 2019)

In Korea, manhwa represent the first step of a transmedia publishing model, where manhwa comic popularity can lead to television or game adaptations and is often the goal for their originators. Despite differences in form, the manhwa transmedia publishing model closely resembles that of Japanese manga (Japanese comics), where popular anime shows like Naruto, Hunter X Hunter, and One Piece that started as manga in Shonen Jump Weekly (a weekly publication that features several different manga), have since also spawned several games, such as J-Stars Victory VS (Eisenbeis, 2014), featuring characters from different Shonen Jump manga in a single crossover fighting game. 
Manhwa and manga that are adapted to animation also generate increased interest in the IP and bring new attention to the comic as well (Jin, 2015). A similar phenomenon is taking place in North America with manga and anime as more and more anime shows are being shown on popular streaming services such as Netflix and Hulu, they are driving demand for the manga which they are based upon (NDP, 2019). There is also a North American manhwa site called WebToon ("WEBTOON," n.d.) that is very similar to comic.naver.com, with the main difference being that it appears to be manhwa in English for a North American audience.

The manhwa comic delivery format and transmedia publishing model is the closest to the model that is being proposed for Gladiotron. The key difference is that Gladiotron will use 3D assets in a 3D web-comic, instead of being a flat, 2D comic. So, the pipeline proposed here is 3D comic $->$ game $->$ animated episodic content with 3D assets being created at the outset and as needed through development on the comic as opposed to $2 \mathrm{D}$ comic -> animated episodic content -> games (Figure 9). 

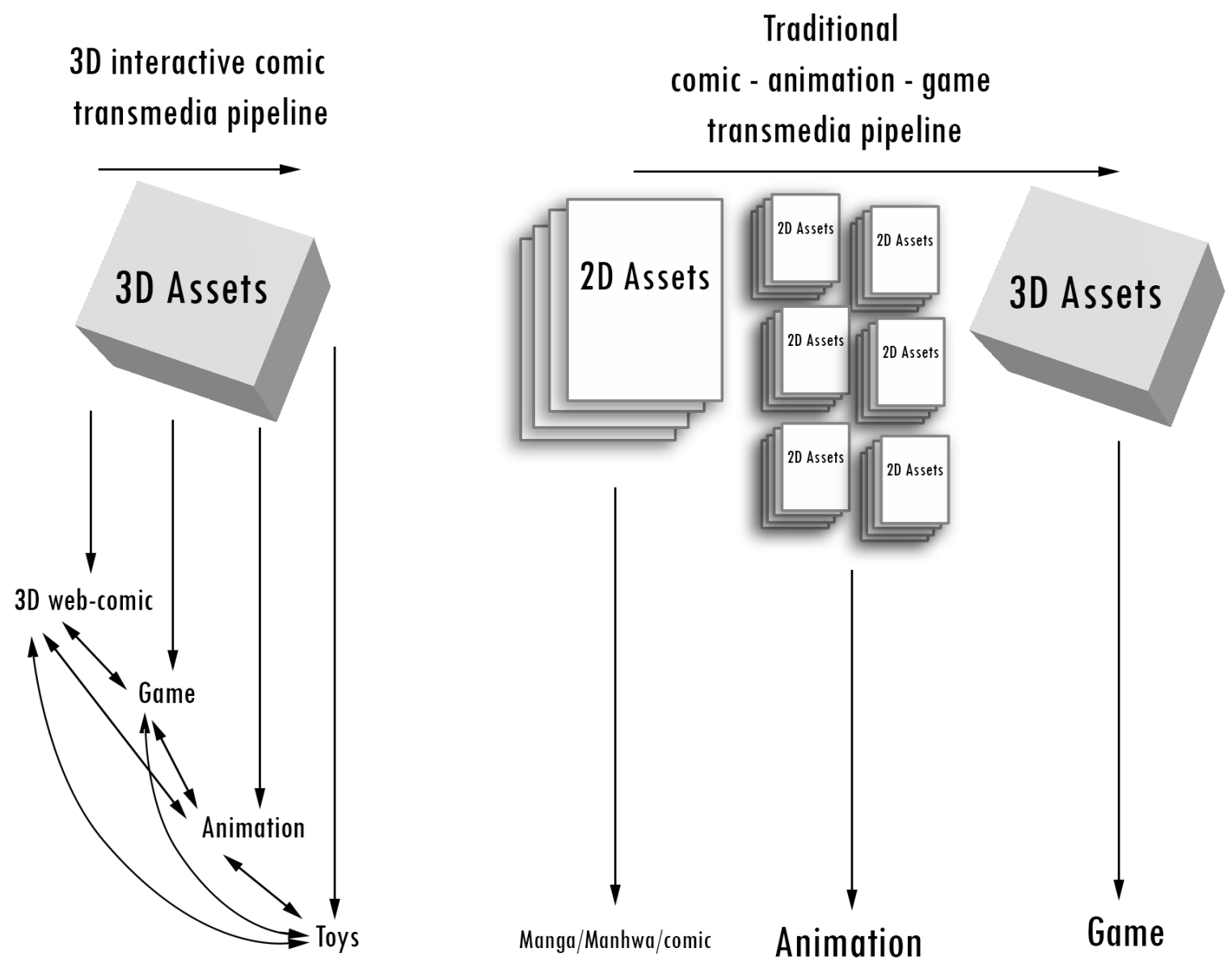

Figure 9 - Difference between Gladiotron proposed pipeline and traditional transmedia pipelines

There are projects which use aspects of 3D in their pipeline, such as Kengan Ashura (Larx Entertainment \& Netflix, 2019), where the manga is $2 \mathrm{D}$ and the show uses $3 \mathrm{D}$ assets. There is also a mobile game based on this project which features some $2 \mathrm{D}$ artwork from the manga (Shogakukan Inc., 2019). Again, Gladitotron will feature a greater degree of asset transferability compared to Kengan Ashura where transferability is limited due to switching between 2D and 3D formats.

The manhwa, Reid (Eui-chul \& Hyun, 2019), uses 3D assets in the comic stage (Figure 8), which could conceivably facilitate animation and/or game development going forward. One key difference between Reid and Gladiotron, is that Reid closely mimics other manhwa in that 
there are no animated or interactive panels present, whereas Gladiotron will have both. Having 3D assets should increase the speed with which the authors of Reid can produce new manhwa content, by removing the time required to draw elements which already exist as 3D assets, which is also a goal for Gladiotron.

\subsection{Real-time Rendering for Animation Production Using Game Engines}

Zafari is an animated children's show that is rendered using the real-time rendering system in the game engine Unreal Engine 4 (Zafari Holdings \& BE3 Animation, 2018). The show is not being presented to viewers in an interactive manner and is instead being prerendered and delivered in a linear format like standard animated children's shows (Figure 10).

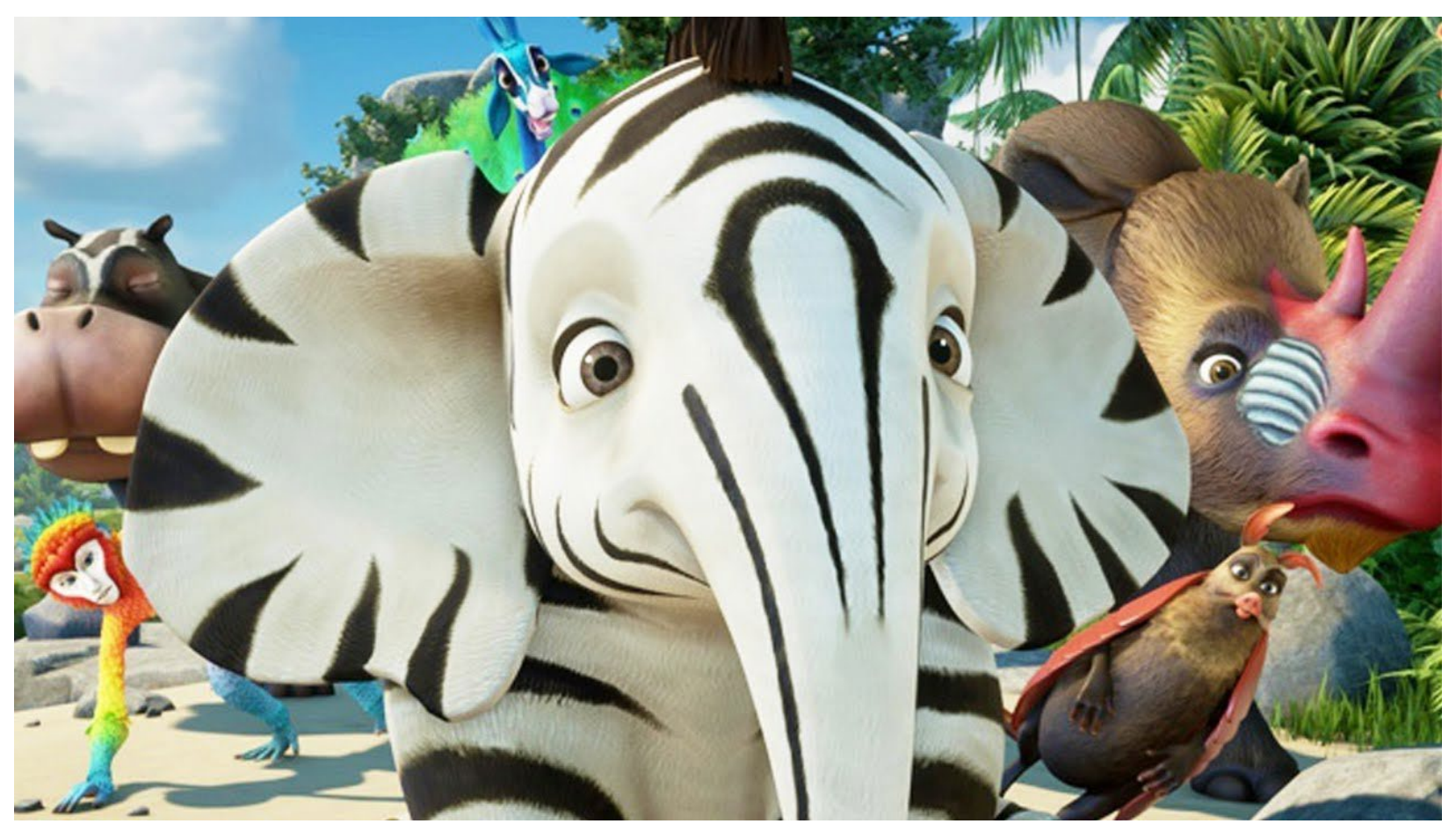

Figure 10 - Still image from the show Zafari (Zafari Holdings \& BE3 Animation, 2018) 
However, since the project runs inside a game engine, there is no reason that it could not be presented to audiences in an interactive manner where viewers could change the camera angle themselves (Failes, 2017). Animated productions are increasingly taking advantage of advances in hardware and software to bring time and cost savings to production (Bak \& Wojciechowska, 2019). The level of detail possible in assets designed for real-time rendering is becoming increasingly comparable to that of assets designed for pre-rendered animation pipelines which are slower and more expensive (Failes, 2017). This makes it feasible now to utilize a gameready asset for animation production as well, especially in the case where a real-time rendering solution is used for animation production (Failes, 2017).

\section{Background of Gladiotron}

\subsection{Overall Project Scope and Intermediate Goals}

As a large-scale project with a final goal of bootstrapping a franchise and releasing seven seasons worth of episodic animation content the full project will take several years to realize and is far beyond the scope of what can be fully discussed here. However, in order to realize the full potential of this project, a few things must happen first. Working backward; the Gladiotron game must first be of high quality, and it should have a sufficient following and fan base in order

to create a self-funded animated show. Moreover, in order to create the game to the quality level required and to again self-fund it, there will have to be a relatively successful crowdfunding campaign. Sufficient funding for the game is the most critical step. It is important to note that funding can also come from a motivated publisher; however, a crowdfunding campaign is preferable because creative control will be retained and crowdfunding itself is a great marketing tool that will help to get the game greater visibility and increase the odds for more sales. Good 
crowdfunding campaigns on Kickstarter benefit from compelling gameplay videos, beautiful art and most importantly, a pre-existing following. In order to have a successful Kickstart crowdfunding campaign, it is vital to begin cultivating an audience for the project now, which is why the decision was made to pivot away from solely developing the game to instead building a userbase. Focusing on the story and building a userbase makes sense because the game is at a good stage currently and can be tweaked and polished while also building an audience.

Increasing visibility will be done by releasing a fixed length, serialized, and free online comic on a weekly or bi-weekly basis. This comic will serve to introduce readers to the characters and world. Therefore, in order to accomplish the more significant tasks of creating and releasing a game and then eventually creating episodic animation to tell this story entirely, the current goal is to market the project and begin building an audience for a warm crowdfunding launch.

\subsection{The Gladiotron Comic}

The comic will take the form of a 3D interactive experience that will serve as an appropriate intermediate step that will directly contribute towards the realization of the full game in several key ways beyond just marketing. Online comics released on a weekly, bi-weekly or monthly basis can gradually build an audience and greatly enhances discoverability (Brubaker, 2011). Further, by making the comic 3D; assets (environments, characters, and animations) can be reused in the game since it will also be a $3 \mathrm{D}$ game. By making it interactive, testing small gameplay mechanics will improve the developer's programming skills which are currently a relative weakness, while simultaneously yielding important insights for developing the game. Additionally, the story and environments can be fleshed out, and ideas can be focus tested 
through audience engagement (polls, comments, and other feedback). An online platform will also facilitate branching paths and dynamic changes based on feedback.

\subsection{The Gladiotron Story}

The most important aspect of this project is its story and the message it delivers. So, while there are multiple planned formats - the characters and story are what pull everything together, and it serves as the common thread that runs through everything. Currently there is a framework in place for the beginning middle and ending and key plot points planned along the way; however, the story needs to be better fleshed out as it is the most essential component to the whole project.

\subsection{Gladiotron Webpage}

Having a Gladiotron project landing page will provide a central place for the 3D webcomic and joining the mailing list. Using the website as a landing point for readers will also allow for merchandise sales by leveraging drop shipping platforms such as Shapeways for 3D prints, Redbubble for t-shirts, prints, mugs, and stickers and will provide a good entry point for any other planned transmedia initiatives related to the IP.

Google Analytics or a similar analytics tool will be set up on the site in order to monitor what kind of traffic the site is generating, which paths people are taking in the 3D web-comic most frequently, and where they might be getting stuck or losing engagement. Extensive user testing will need to be done to ensure that users know how to navigate content, that the audio is appropriate and that the story has the desired effect. User testing will also be done to poll users 
on how they feel about the story, the format, the interface, loading times, the characters and whether or not they found anything confusing.

\subsection{Reaching the Audience}

In order to reach the target audience, in this case - boys of African descent, it is essential to feature characters that visually represent them because physical similarity enhances player identification with the in-game avatar (Cicchirillo \& Appiah, 2014). Also important is that the character portrayals are positive and not offensive; otherwise players who strongly identify with the characters may experience negative affect towards the avatar (Cicchirillo \& Appiah, 2014). There is a concern that non-Black audiences might feel alienated and not want to engage with the project because the main character is Black, so to mitigate that, the cast of characters will be multicultural and represent a variety of ethnicities. Also, players not in the target demographic

will be able to appreciate the content due to a phenomenon called cultural voyeurism that allows people outside the demographic to get a peek inside another culture's reality (Cicchirillo \& Appiah, 2014).

\section{Methodology}

\subsection{Technology}

\subsubsection{Three.js and Babylon.js}

Three.js and Babylon.js are two prominent JavaScript libraries that make use of the OpenGL ES 3.0 (WebGL 2.0) API. Either would work for the purposes of what is being done in 
this project, however, Babylon.js was chosen because of its focus on game development and because its use of the HTML canvas element was more transparent. These libraries work with the HTML canvas element to make dynamic and interactive 3D scenes. They also drastically reduce the complexity of writing code to implement 3D work within a browser. While still relatively complex and while still requiring some level of understanding about programming concepts, using a JavaScript library increases the output of the individual because a lot of the important functionality, such as working with interaction events and loading and rendering 3D assets and animations, has already been figured out.

\subsubsection{GITF file format}

The $g l T F$ file format is a human readable $J S O N$ (JavaScript Object Notation) file format designed to store all geometry, texture data and animation data in one easy to use package to deploy on the web. There is also a compressed version of glTF called $g l b$, which has a smaller file size. This file format can be loaded into a Three.js or Babylon.js project to show sophisticated characters or props online. The goal of the format is to create the JPG equivalent of $3 \mathrm{D}$ assets - something lightweight, easy to package and share. While not essential to displaying 3D models on the web, this file format greatly speeds up the iteration process where entire scenes can be swapped just by changing just one file. The glTF format is described by the Khronos group as follows:

$\operatorname{glTF}^{\mathrm{TM}}$ (GL Transmission Format) is a royalty-free specification for the efficient transmission and loading of 3D scenes and models by applications. glTF minimizes both the size of 3D assets, and the runtime processing needed to unpack and use those assets. glTF 
defines an extensible, common publishing format for 3D content tools and services that streamlines authoring workflows and enables interoperable use of content across the industry (“GlTF - Runtime 3D Asset Delivery,” 2013).

\subsubsection{D content creation tools}

To add to this, there are 3D content creation tools such as Blender that export to the glTF/glb format. Blender also has a Babylon.js exporter as well which exports a similar file format to gITF with additional scene data related to a Bablylon.js project such as collision, fog effects, and camera movement style. 3D Coat is also being used for character sculpting, retopology and texture painting. Marmoset Toolbag is being used for previsualization of assets and glb export.

\subsection{Gladiotron Design Choices}

The following design choices have been implemented into the Gladiotron story and overall development process.

\section{PRINCIPLE \#1 - ALLOWING FOR CHOICE}

Allowing for choice in the comic will give Gladiotron the opportunity to depict consequences attached to choices in a way that encourages users to make decisions that are positive by having positive choices lead to progress and negative choices leading to an unfavorable outcome and/or stalled progress. Gladiotron's level of interaction will be similar to 
point-and-click adventure style games in that the primary method of interacting with content will involve clicking, tapping or dragging elements within the scene. Simple interactions are desirable in order to accommodate mobile users who might not have access to a physical keyboard or gamepad. Content will be structured in a way that allows users to make choices that lead to different outcomes. For example, a user can be presented with two possible responses to a problem where pressing on one option or another will lead them to a page showing the result of their decision. This can be done using alternate dialog options, different clickable scene elements, or by presenting locations that users can visit in any order. This method will allow users to piece together information and facilitate revisiting locations in order to unlock further progress in the story. Additionally, we can have panel-based puzzles where users must move things around within the 3D environment in order to reveal things that are hidden or reach some other condition in order to progress.

\section{PRINCIPLE \#2 - SHOW THE CHARACTERS WORKING THROUGH STRUGGLES}

The current strategy is to show the main character going through struggles in the pursuit of his goals. This is a common theme in Shounen manga (action comics in Japan usually targeted to boys 12-18) such as Naruto, Hunter X Hunter, and Dragon Ball, where the male protagonist gets stronger through hard work and persistence; growing as the story evolves despite numerous hardships and setbacks along the way, requiring him to regroup and work harder to progress. These stories are earmarked by the main character's persistence and motivation to improve when they encounter failure (Chatterjee, 2019), in addition to storylines with a definitive ending that see the characters age and grow over time (Japan Deluxe Tours, 2016) as opposed to American Comics (popularized by Marvel and DC) which see the characters 
remaining the same throughout and the series being refreshed periodically, in more of a soapopera style of storytelling.

As a story that showcases character growth and coming to grips with the consequences attached to certain choices, it makes sense to have the story of Gladiotron borrow heavily from Shounen manga, which better suits the goals for the project. Beyond that, Gladiotron will show the characters finding different paths to their goals when progress is blocked. When they encounter seemingly impossible obstacles to overcome, the characters will be shown to lose hope. At which point they will reflect upon past successes in similar circumstances or advice they have received in order to find a new way forward. This will be done in order to portray Commander Bean and Sergeant Sprout as underdogs who must overcome great odds to reach their goals, which in turn provides the important phycological benefit of increased hopefulness for the audience (Prestin, 2013). This will be primarily directed towards adolescent males through the Commander Bean character and adolescent females through the Sergeant Sprout character (Prestin, 2013).

\section{PRINCIPLE \#3 - BE ABLE TO ENJOY THE CONTENT TOGETHER}

It is also a goal for the content to be consumable by intergenerational audiences, which are audiences that span different age groups as could be found watching a Disney or Pixar film. This can be done by creating a story and characters that parents and youth can both appreciate. This will be done by ensuring that the content is not overly mature; limiting violence and course language; and omitting nudity and sexual content. While the primary target audience is African American male youths, the project will utilize visual design principles that are 
universally appealing, and the story will speak to the human condition in order to be relatable to audiences of all ages and ethnicities.

PRINCIPLE \#4 - MAKE SURE ELEMENTS FROM THE COMIC SPEAK DIRECTLY TO THE GAME

One of the primary reasons for making the decision to create a 3D interactive comic has been to create a rapid asset development pipeline to generate assets for use within the game.

Otherwise, the comic would provide less of a direct benefit to the game outside of marketing and visual development, in which case either a 2D comic or no comic at all would be developed for the project. Character models can be developed once and used for the comic, game, toys, and other merchandise such as posters and prints.

Geometry will be created such that they will be high enough resolution for use in animation, games, and for the comic, while also being low enough resolution to be useful in realtime rendering environments as in the case of the game and the comic. Additionally, the comic will be best served by polygon counts that are relatively low in order to keep file sizes low in order to reduce download times. Additionally, the rigs will be created in a way that is good for real-time rigging environments. Therefore, rigs should be primarily made up of bones and blendshapes/shapekeys, which are effective in both real-time rendering situations and prerendered situations.

Textures will likely be the only component that might require two different versions. One for the web and one for the game. The reason for this is the number of texture image files associated with modern game assets. There are usually at least two 32-bit image files that are at 
least 2,048 pixels by 2,048 pixels in size for most assets. This is not problem for WebGL, but these texture images do increase the size of a glb file quite substantially and as a result cause content to load more slowly due to increased download times. For this reason, it might be best to down sample textures or omit some textures where possible for the purposes of the $3 \mathrm{D}$ webcomic. While the original textures can be used for the game and pre-rendered animations.

Control schemes and user interface design choices can also be adapted from a 3D interactive comic into a game; with the game serving as a public facing testing ground for interaction design choices which can help determine what works and what does not through user testing; the results of which can be implemented into the game where appropriate.

\section{PRINCIPLE \#5 - ENSURE ALL ELEMENTS ARE AS MARKETABLE AS POSSIBLE}

Artwork and 3D assets will be created that can be used for other purposes such as marketing materials and merchandise such as inspirational Instagram posts that can double as posters sold through an online store as versions adorned with an inspirational quote or as artwork alone with no text (Figure 11). 


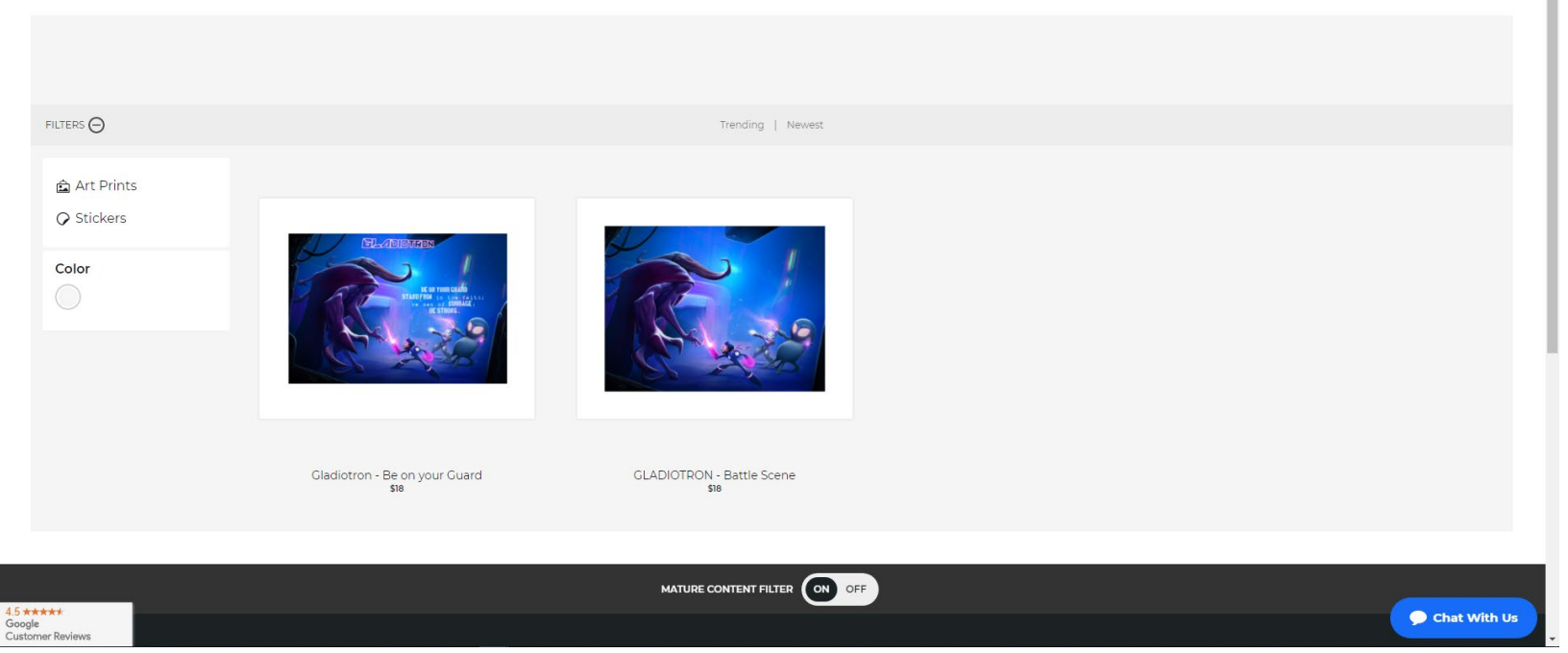

Figure 11-Images posted to social media can be also be sold as merchandise

Conceptual art and character models will also be made as merchandise as well. All main characters will be posed in Blender and prepped for printing using 3D Coat's digital sculpting tools in order to ensure that the meshes are 3D print ready (Figure 12).

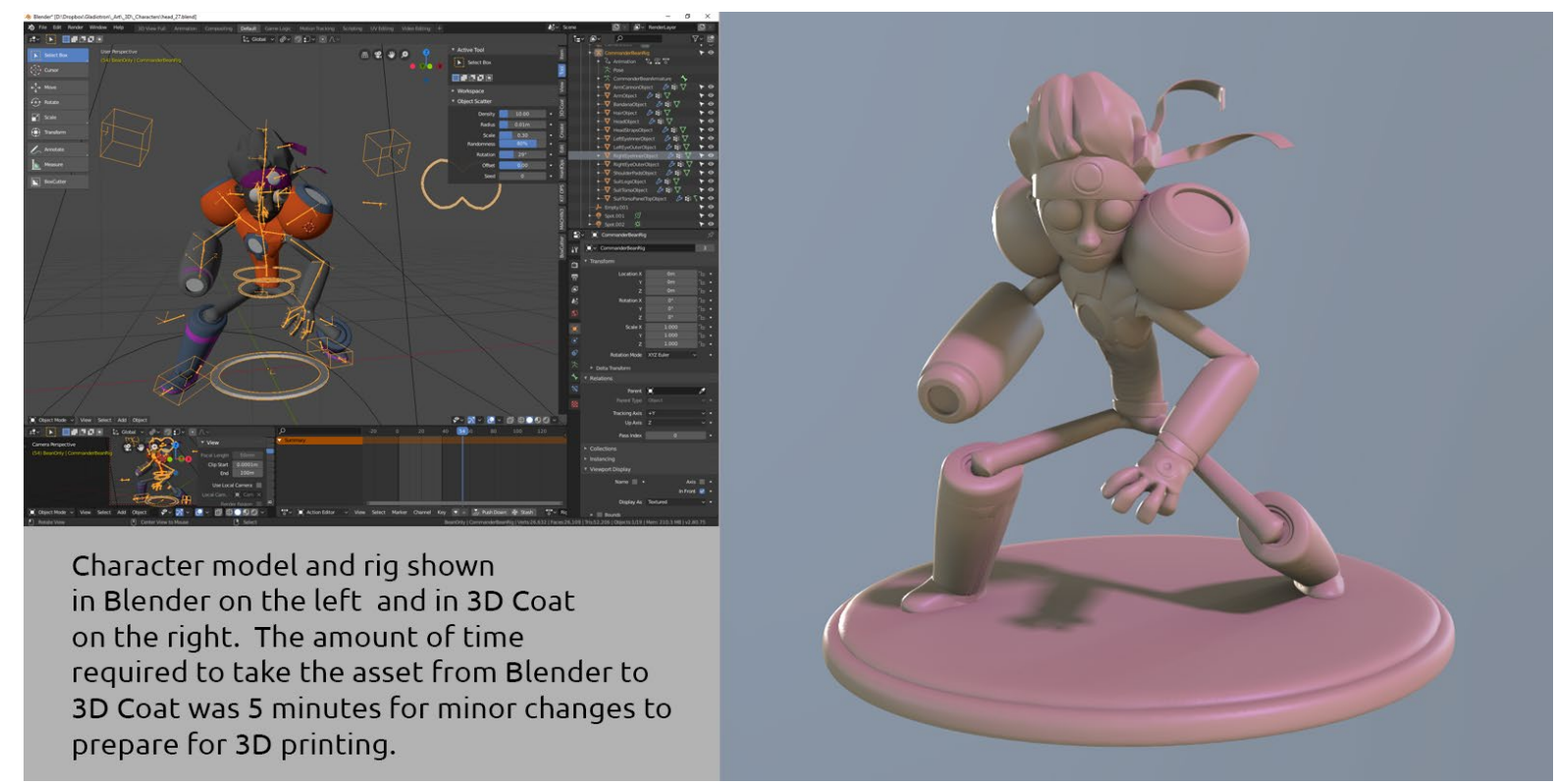

Figure 12 - Gladiotron main character, Commander Bean, being prepared for 3D printing 


\subsection{Agile Development Process}

Throughout the course of this project, an agile development cycle was adopted in order to stay flexible and open to new information as it arose. Agile development has been defined as follows:

Agile development is Individuals and interactions over processes and tools

Working software over comprehensive documentation

Customer collaboration over contract negotiation

Responding to change over following a plan ("Manifesto for Agile Software

Development," n.d.)

Agile development is the preferred method because it offers the benefits of speed-to-market, greater flexibility with the ability to respond to changes quickly, and most importantly, better user engagement as a result of the greater visibility and ability to respond quickly to user feedback (Waters, 2007).

The Gladiotron development team met two times per week, once to discuss the overall development on the comic and the project as a whole and another time to focus on the development of the videogame. There were two different teams working on different but related tasks and the meetings helped to keep everyone abreast of developments while quickly identifying problems and opportunities as they arose, allocating resources accordingly. This was handled largely through a series of sprints, which is a short time period where a team works towards the realization of a goal (Rehkopf, n.d.). These lasted between one and two weeks in duration, wherein the team would determine the next most important course of action, discuss who was responsible for what and then work towards it's realization by the end of the sprint. 
During the sprint, the team would communicate through a Discord server (a messaging and team organization application popular with game developers) that was setup for Gladiotron related communication.

In terms of the Gladiotron web-comic, reader feedback will be listened to and incorporated wherever possible without losing focus on the overall thrust of the story. Story content, and interaction design, will be adjusted based on feedback received through the website and in person during planned user testing.

The key reasons that allow this process to remain agile during development are the ability to gather meaningful feedback, and act on it quickly. Through the website, user testing sessions, and workshops with our target demographics, we will be able to get valuable feedback on the Gladiotron web-comic; and because of the way our asset pipeline has been set up, and the modular nature of the live content on the website, making changes is only slightly more involved than making an update to a blog in a content management system. This allows us to get feedback and act on it quickly.

\subsection{Realtime Rendering and WebGL}

With the advancements in real-time rendering technologies, it is now possible to generate great looking computer graphics that in some cases are hard to distinguish from real-life. This is traditionally the domain of computer games, console games, and mobile devices. However, with the advances in WebGL, high-quality 3D animations, VR, and AR can be viewed on the web by leveraging the WebGL 2.0 standard using current technology.

From the Khronos Group website (developers of the WebGL standard): 
WebGL is a cross-platform, royalty-free web standard for a low-level 3D graphics API based on OpenGL ES, exposed to ECMAScript via the HTML5 Canvas element. Developers familiar with OpenGL ES 2.0 will recognize WebGL as a Shader-based API using GLSL, with constructs that are semantically similar to those of the underlying OpenGL ES API. It stays very close to the OpenGL ES specification, with some concessions made for what developers expect out of memory-managed languages such as JavaScript. WebGL 1.0 exposes the OpenGL ES 2.0 feature set; WebGL 2.0 exposes the OpenGL ES 3.0 API.

WebGL brings plugin-free 3D to the web, implemented right into the browser. Major browser vendors Apple (Safari), Google (Chrome), Microsoft (Edge), and Mozilla (Firefox) are members of the WebGL Working Group. ("WebGL - OpenGL ES for the Web,” 2011)

WebGL makes all forms of 3D on the web possible. Without it, this project would not be possible. 


\section{Product Described \& Design Strategy Explained}

The Gladiotron project required the use of the several different tools and technologies to bring everything together (Table 1). They are listed here.

\begin{tabular}{|c|c|}
\hline \multicolumn{2}{|c|}{ Tools and Technology } \\
\hline Concept art & - $\quad$ Photoshop and TVPaint \\
\hline 3D asset creation & $\begin{array}{l}\text { - } 3 \mathrm{D} \text { Coat and Blender for 3D asset creation and animation and } \\
\text { - Blender and Marmoset Toolbag for export }\end{array}$ \\
\hline Music and Audio & $\begin{array}{l}\text { - Propellerhead Reason for music composition and } \\
\text { - } \quad \text { Reaper for audio recording }\end{array}$ \\
\hline Website & $\begin{array}{l}\text { - } \text { Processwire (using PHP. Mysql, JavaScript, HTML, CSS) } \\
\text { - UIKit3 (front-end UI/UX library) }\end{array}$ \\
\hline WebGL & $\begin{array}{l}\text { - Babylon.js to make panels interactive and an interchange } \\
\text { format called gITF } \\
\text { - glTF and glb to migrate 3D assets to the web }\end{array}$ \\
\hline
\end{tabular}

\subsection{Website Development}

\subsubsection{WebGL framework}

Once the decision was made to create a 3D web-comic, the next choice was to find an online home for it. Early on, many options were entertained, such as Sketchfab, which is a platform that is home to all types of $3 \mathrm{D}$ content and has a very larger following. It also has a strong community where people are able to easily follow, like, and share content. While 
Sketchfab was initially explored, it was quickly ruled out for a few reasons. First, was the fact that the level of interaction was limited (Verge3D, 2019). Secondly, it is not an open platform. It is a proprietary tool and there would be limited control over how the work would be displayed on external sites. Just removing the Sketchfab watermark on embedded versions of the page would cost in excess of \$249 USD per month (Figure 13) paid annually, which is far beyond the budget for this project.

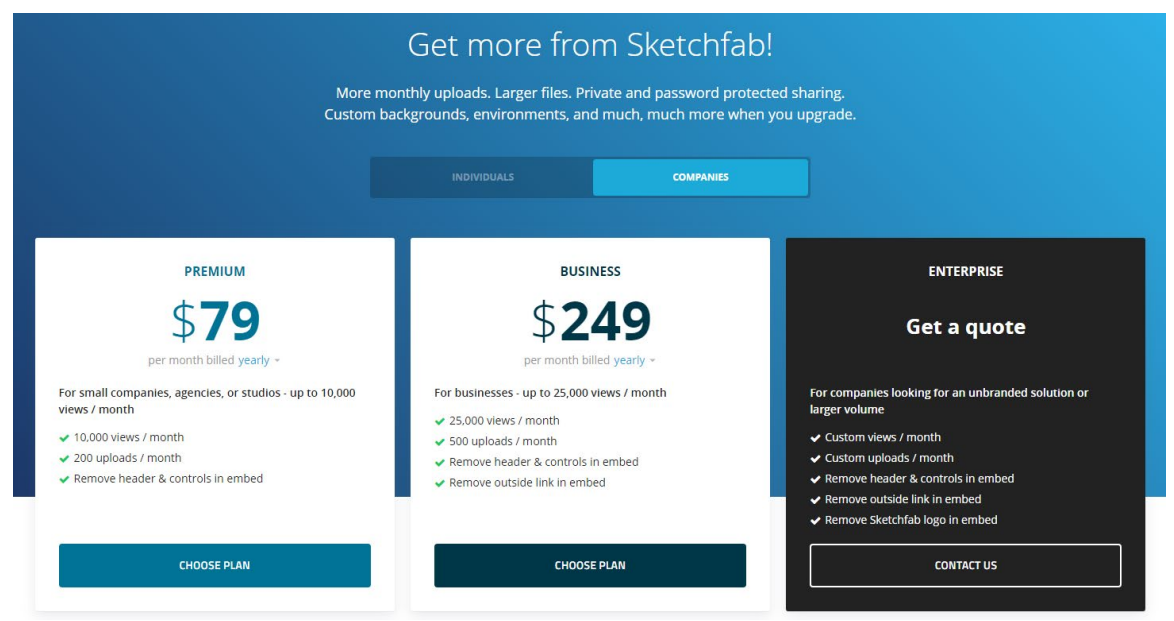

Figure 13 - Sketchfab monthly pricing in USD (Kickstarter, n.d.)

Pricing was a primary reason for exploring non-proprietary, open-source solutions such as Three.js, which is what we were initially leaning towards before discovering Babylon.js on a site called HTML5 Game Devs where the consensus was that Babylon.js was the best choice for 3D online games as the more game-oriented opensource WebGL Javascript library out of Three.js and Babylon.js (HTML5 Game Devs, n.d.). Prior to settling on Babylon, Unity and Unreal Engine 4 were also considered, but quickly dismissed because projects exported from them do not integrate as cleanly into a web page as a native WebGL solution such as Three.js or Babylon.js would. Additionally, we experienced export problems using both Unity and Unreal. 


\subsubsection{Content management system}

There were a few goals for the website that would dictate the strategy used in its creation.

1. It should be easy to maintain and iterate on when necessary

2. It should be extensible

3. It should allow for user feedback and commenting

4. It should have an address that was unique and relevant to the project

5. It should be modular - meaning, it should allow for creating reusable templates for a variety of content

6. It should be flexible enough to work with a WebGL library such as Three.js or Babylon.js

The first thing that needed to be done was to choose a content management system to work with. Something that would allow for blog style updates and archiving of data, while being adaptable enough for a serialized 3D Comic without having to dig through layers of code. Drupal and Wordpress, were considered, but Processwire was ultimately chosen due to its flexibility in terms of presenting content as it is similar to creating regular websites with HTML and CSS. Processwire also has many of the same benefits of a the more popular CMSs without having to learn as much about the idiosyncrasies of a complex system as would have been the case with Drupal or Wordpress. Once Processwire was chosen to build the site, the Gladiotron website was created using placeholder text and images. Some research went into understanding the Processwire systems which is written in PHP, so developing familiarity with PHP was also required.

\subsubsection{Integrating Babylon.js with Processwire}


The next step was to integrate one of the WebGL libraries into one of the pages to prove that $3 \mathrm{D}$ would work. This caused some initial problems that needed to be worked out. The first problem was noticed when a Three.js demo scene copied into a Processwire template file caused unexpected results where the 3D appeared on top of the website masthead. The 3D scene did work, despite the overall page not rendering properly.

Further investigation revealed that Processwire's template system, while relatively straight forward allows for the prepending and appending of other templates when rendering a page. In the case of the blog profile that I was adapting, there was a_main.php file that was set up to automatically appended to every template at render time. This had been setup in the config.php file in the version of Processwire that I was using. So, when I created a custom template to display the 3D content, the page header graphic and links ended up being appended at the end of the page through the _main.php file. Processwire allows HTML elements from the template file to overwrite elements with the same name and id tag in the appended_main.php file, thereby allowing web developers to create custom template files that are capable of overwriting certain things that would otherwise appear on all pages from _main.php file. This was useful because the _main.php file contained the bulk of the markup required to render a page. Overwriting parts of it would keep template files small and they could be used to augment and overwrite certain elements in specific ways in a very modular system. Once realized, this initially appeared to be the ideal solution for the goals of this project.

Unfortunately, more problems arose when trying to load JavaScript code dynamically from within text fields set to display in the template and overwrite the fields in the _main.php page. The problem happened because of the way Processwire loads pages by pulling partially from one source and then from another source before compiling all sources together and 
rendering it to the browser. This caused the JavaScript scripts to look for things that had not been rendered yet. This had the effect of pages that would not display WebGL anymore. This was a major problem, because while it would work properly when the JavaScript was placed directly into a template file's source code, that would immediately destroy the modularity required to make the comic serializable and easy to update. As each page would require a unique template file for every single $3 \mathrm{D}$ comic page as opposed to one template file that could be passed different scripts for each panel in a modular system. Thankfully, there was a solution. Through the use of a plugin called Hanna Code, it was possible to write JavaScript and save it as a Hanna Code code block with a short identifier that could then be embedded into a text field within a template file. The Hanna Code module was developed by the creator of Processwire for scenarios where web developers wanted to create modular blocks of code that could be embedded into any template file and load properly.

There was one final issue that popped up during development on the website which had to do with getting assets to load properly through the Babylon.js loader which by this point had been chosen over Three.js due to its game specific API. The problem was having Babylon.js and Processwire to work together. The way Processwire works is that in order to get dynamic content to load in a template, there is a requirement to put a PHP tag in the template source code that would take data from a text field attached to the template and load it where the PHP tag is located when the page renders in the browser. These tags can contain anything from the title of the page, to an image, to links, to body copy. In this case, in order to retrieve assets to load into Babylon's scene structure, a relative path to the assets location on the web server is required. Generally, this is straightforward, but Babylon's asset loader requires a string name as a path to the file in JavaScript, while Processwire, being a PHP dynamically loading CMS does not have a 
fixed directory structure the way a static website would. Therefore, it uses PHP tags to locate relative paths. So, to get it working properly, PHP tags would have to be embedded into the JavaScript string to generate the relative path to the asset for Babylon.js. Thankfully this was not a big issue at all because with PHP being a preprocessor language, the PHP tag resolves to text prior the JavaScript code. Once this was worked out the the HannaCode scripting language was set as PHP code as opposed to JavaScript in use the echo function to write out the Babylon code in JavaScript (Figure 14).

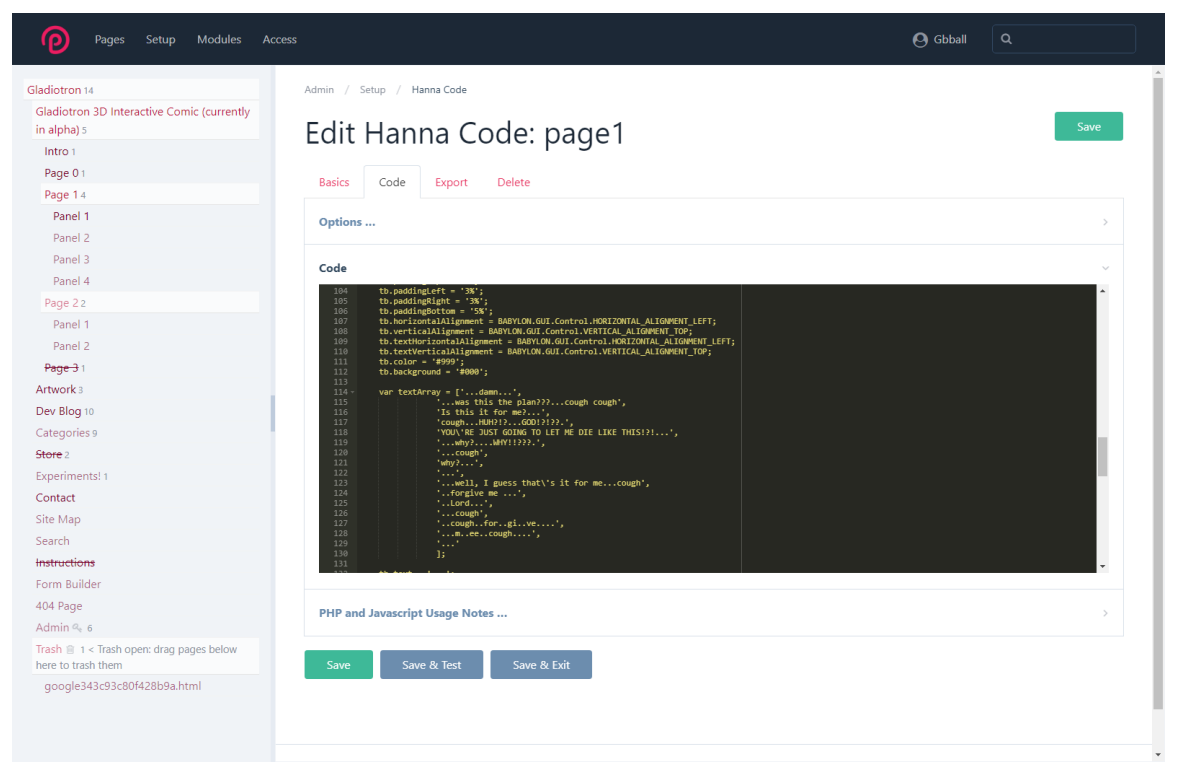

Figure 14 - Showing PHP and JavaScript code in Hanna Code module in Processwire CMS

While it took a little while to set up, once the website framework was functional and modular, it would require very few changes to produce the comic. Posting new pages and panels would be a relatively straight forward process of implementing a Hanna Code script's tag name (Figure 15) and placing it within a field (Figure 16) on a page based on a template file, which would then update the template with the PHP code from the Hanna Code script when the page was being rendered to the browser. 


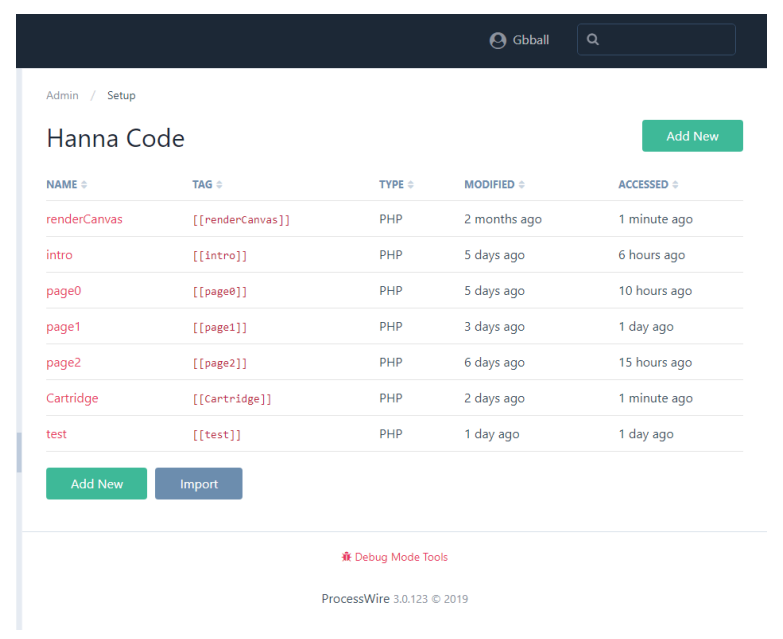

Figure 15 - Hanna Code script tag names

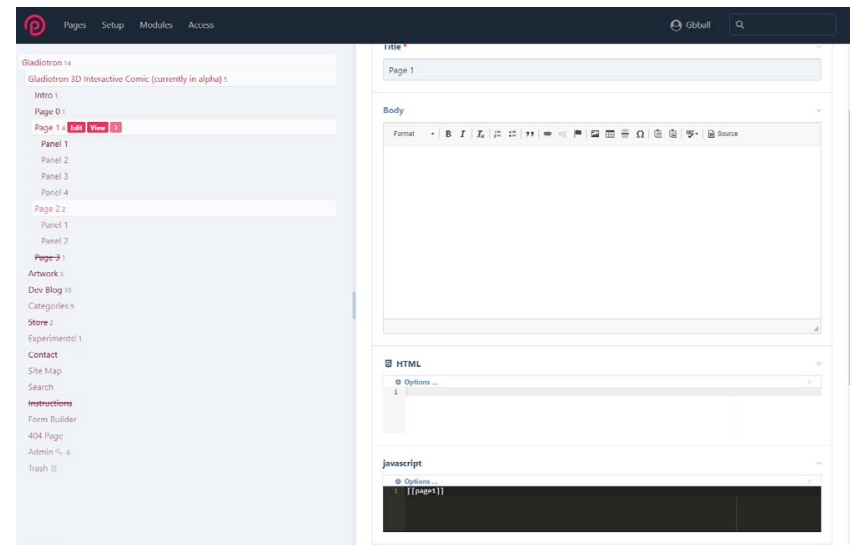

Figure 16 - Hanna Code tag embedded into the field of one of the sites pages

The website took 4 months to setup as intended, on a part-time basis with intermediate coding experience and being brand new to both Babylon.js and relatively inexperienced with both JavaScript and PHP.

Using a flexible content management system to manage users and updates, along with a WebGL library and a web friendly interchange format to transfer models to the web has made it possible to utilize the web page as a canvas for a dynamic, interactive experience that straddles the line between comics, games, and animated stories. 


\subsection{Asset Creation Pipeline - Blender and gITF}

\subsubsection{Asset requirements}

Assets created for the project should be optimized for real-time rendering environments such as on the web and in games. Optimizing animations for pre-rendered animations which are pegged for future development were not a major concern because real-time rigs are more restrictive than pre-render rigs. Making the rigs for real-time rendering first automatically makes them eligible for pre-rendered animation. The main character from Gladiotron has been the primary focus in terms of asset development. He appears first and more frequently than any other character or model required for the 3D web-comic. His model and rig have been completed and they are already working in the 3D web-comic and the game with all animations. This will be the case for the other playable characters as well; who will all need to be developed for the 3D web-comic, which in turn will make them ready for use in the game. To further augment this pipeline optimization, the characters will use the same rig which will allow for seamless transferring of animations from one character to another which is already a common technique used in game development. The goals for the assets were as follows:

1. Keep scene sizes below 10 megabytes for fast loading.

2. Assets optimized for real-time animation systems.

3. Use bone-based animations with shapekeys for facial expressions and breathing.

4. Create a detailed polygon model for the character to avoid heavy requirements for texture maps, which would quickly increase the file size.

5. Bake lighting into the environments wherever possible to ensure that scenes look good. 
6. Use custom parameters on the armature as drivers for shapekeys on individual meshes in order to avoid unintended animations appearing in Babylon.

7. Ensure assets are easily adjustable and ready and re-export for new scenes in the comic.

\subsection{Asset Pipeline Development}

The asset production pipeline was another component to work out in order to prove that this would be possible. Blender was chosen as the primary asset creation and animation tool and the compressed version of the gITF file format called glb was chosen as the primary interchange format for getting assets loaded onto the website. It soon became apparent that this was not going to be a straightforward process and that not all rig functionality would translate from Blender to glb. Several tests were done in both Blender 2.79 and Blender 2.8 to determine if one version was better than the other for exporting. Test results were essentially the same in both. Blender 2.8 was ultimately chosen because it has some benefits in its modeling workflow.

It was discovered that there is also a Babylon.js exporter for Blender in the .babylon file format, but it was quickly abandoned because it was far too unstable and frequently failed during export and when it did work, animations would not play.

This is when glb was chosen as the primary exchange format for $3 \mathrm{D}$ web content and the Blender to glb export process was explored more deeply.

When exporting bone-based animations from Blender, it was found that unchecking inherit rotations on certain bones was not being respected by the glb exporter, so to fix this, bone constraints were used to copy the location of a certain bone without copying its rotation. The remaining bones in the hierarchy would then be made children of the bone constrained to the location to rectify the issue (Figure 17) 


\section{Rigging issues on exported glTF/glb files}

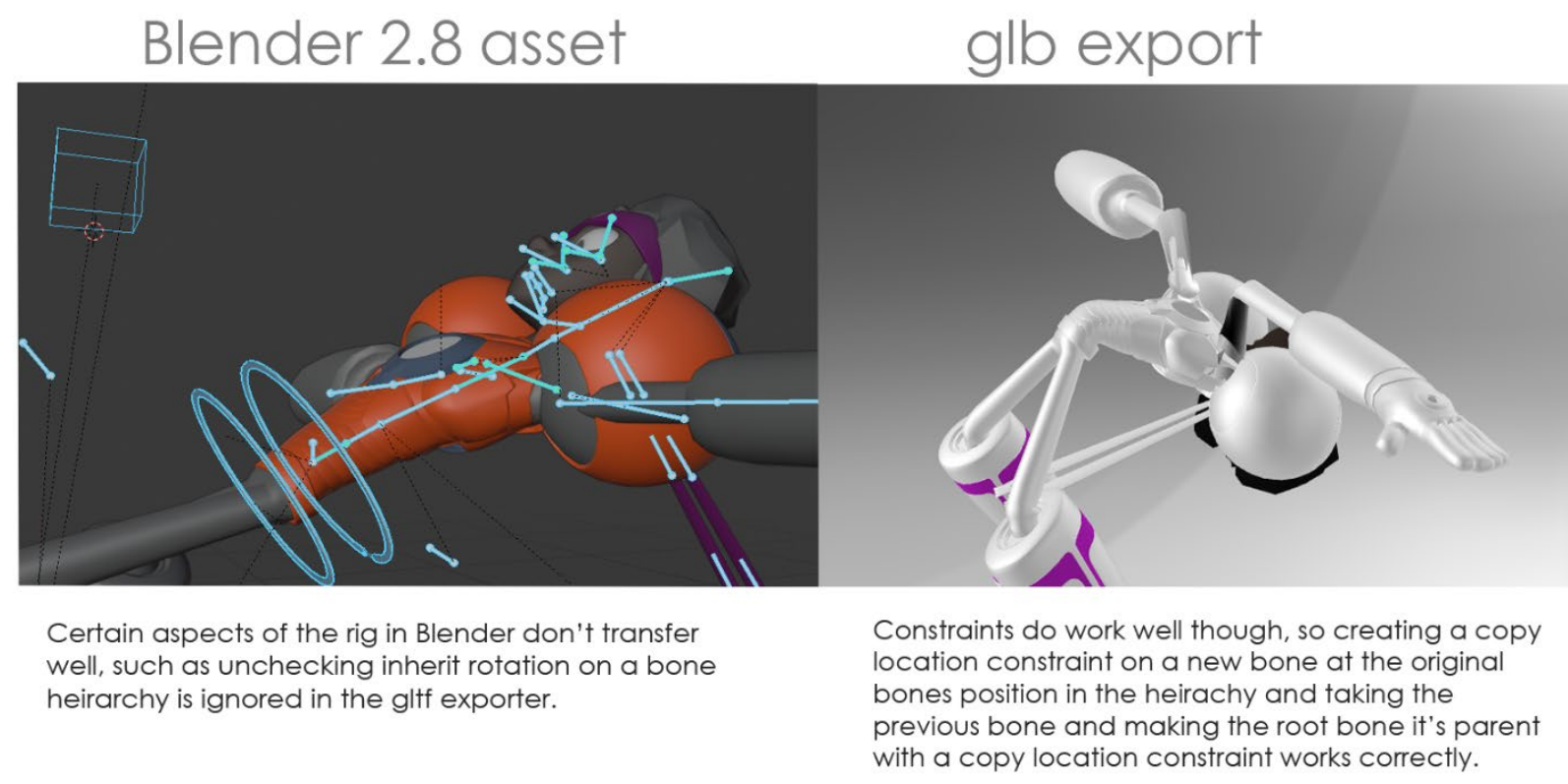

Figure 17 - Non correspondence of Blender rig and animation and glb export

Another issue is with actions (the way Blender saves animation data) is in regards to the association with armatures and bone-based data. They can also be assigned to meshes on their global transform node or on shapekeys interpolations between two or more different mesh positions. When exporting to glTF or glb, if there is an animation applied directly to a shapekey channel on a mesh, that animation data will be given a name and export alongside armaturebased actions; causing havoc on the mesh. Babylon appears to try to take the shapekey animation data and apply it as an armature action, which causes a nonsensical animation to run. This was difficult to troubleshoot because armature based animations and shapekey animations are stored in different places in Blender so it was confusing to see the shapekey animation playing by default on the glb file in Babylon when it is not listed as an animation in the list of named actions in the Blender file. Once these issues have been resolved and the rig is setup properly to export 
to $\mathrm{glTF} / \mathrm{glb}$, the pipeline becomes fairly straightforward and created assets are quickly transferable from Blender to the website. glb files can be loaded from the webserver through the Hanna Code scripts.

Everything on the asset side ultimately worked out well, as assets that have been prepared correctly flow through the pipeline smoothly. One small issue is the amount of time it takes to export a web ready glTF/glb asset from Blender. It takes several minutes to export a glTF or glb file with animation data from Blender which represents a disruption the overall speed of iteration. The delay is not so long that it is a major issue, but it can cause problems when an animation is being tweaked, because adjusting an animation in Blender, exporting as a glb and testing online several times in a row magnifies the issue. This is something that is more of an annoyance at this stage than a major concern. However, it is something that will need to be monitored if exported animated sequences get longer and more complicated.

Marmoset Toolbag is a real-time render engine that was also used for glb export as well. The export process in Marmoset Toolbag was very quick, only taking a matter of seconds, if that. However, the big drawback is that it does not export animation data. Only geometry, textures and materials. For this reason, exporting from Marmoset Toolbag will be useful for environment and static prop exports, while Blender will still be used for animated character assets. Other tools will be explored to see if greater efficiency can be achieved when exporting animated content to the $\mathrm{glTF} / \mathrm{glb}$ file format. 


\subsection{Planning}

Additionally, in order to create a plan for how the comics should look and how the story would unfold, a synopsis was written and thumbnail sketches (Figure 18) were created to help plan out the story.

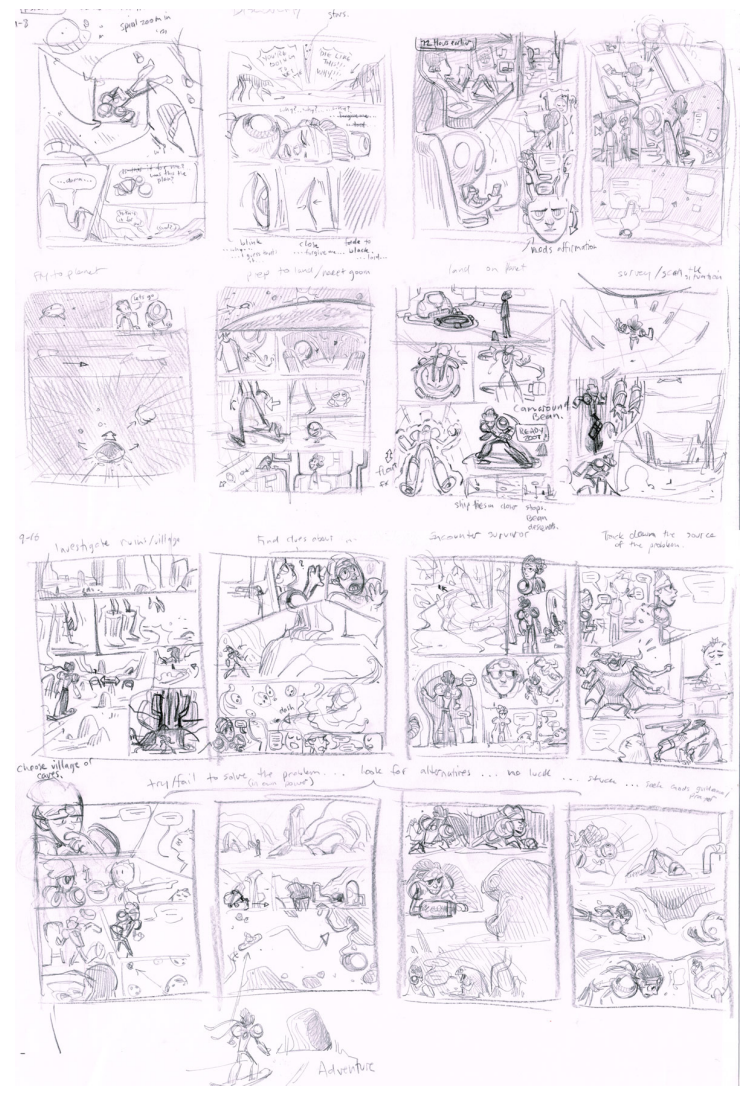

Figure 18 - Thumbnails used for planning the 3D web-comic

The thumbnails provided a breakdown of what would be required in the comic going forward, including what kind of functionality the characters would need to have and in what order the characters would appear. This informed the decision of when to begin developing certain assets. Creating thumbnails like this serves as a valuable roadmap for the story as it progresses, and it is something that will continue to be incorporated into the workflow going 
forward. The amount of time spent on the thumbnails was on average two hours for an eight page break down, which translates to a minimum of 8 weeks of planned web-comic content updates.

\subsection{D web-comic}

With the website in place, the comic planned out, the asset pipeline working, and with the primary character finished, the first few panels of the comic were placed online for feedback primarily to test for usability. Feedback received showed that the comic worked as intended, despite it not being in its finished state. The comic even in its unfinished state came together fairly late in this process. In its current incarnation, it serves as a proof of concept as opposed to the polished finished project we are working towards. Early indications show that iterating and transferring assets to a game engine work smoothly, which were two of the key goals for this project.

The landing page of the Gladiotron website features a concept art scene from the project with a menu at the bottom (Figure 19). When users scroll down, they will see a text description of the project with sections detailing the 3D web-comic, the game, and the overall project. 


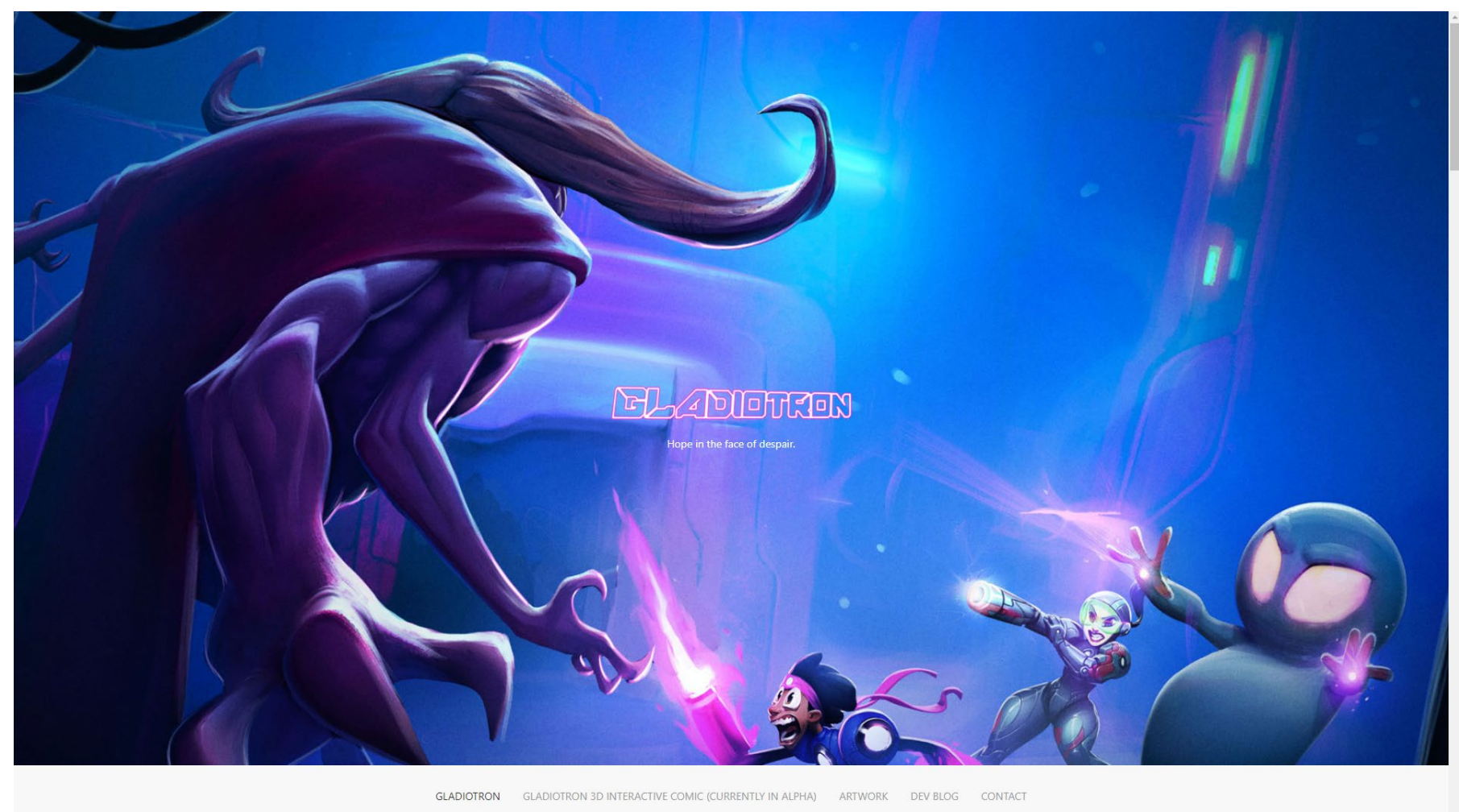

Figure 19 - Gladiotron landing page

The beginning of the 3D web-comic is a panel which allows the user to move the camera using mouse keyboard or touch input (Figure 20). There is providing information on how to interact with the experience. Currently, a single mouse click or finger tap advances the text and a double click moves to the next page. The page features a robot character that is also being used in the game. The asset has the same geometry, rig, and textures as the version used in the game. The file size is relatively small, but it might be further optimized to decrease download and load times on the website. This character was initially used for testing purposes, but has been retained because it was decided that it could be used here for introductory purposes. 


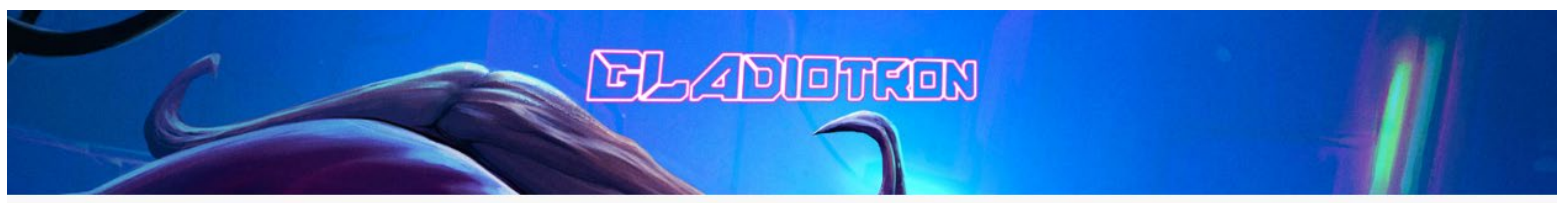

GLADIOTRON GLADIOTRON 3D INTERACTIVE COMIC (CURRENTLY IN ALPHA) ARTWORK DEV BLOG CONTACT

Gladiotron / Gladiotron 3D Interactive Comic (currently in alpha)

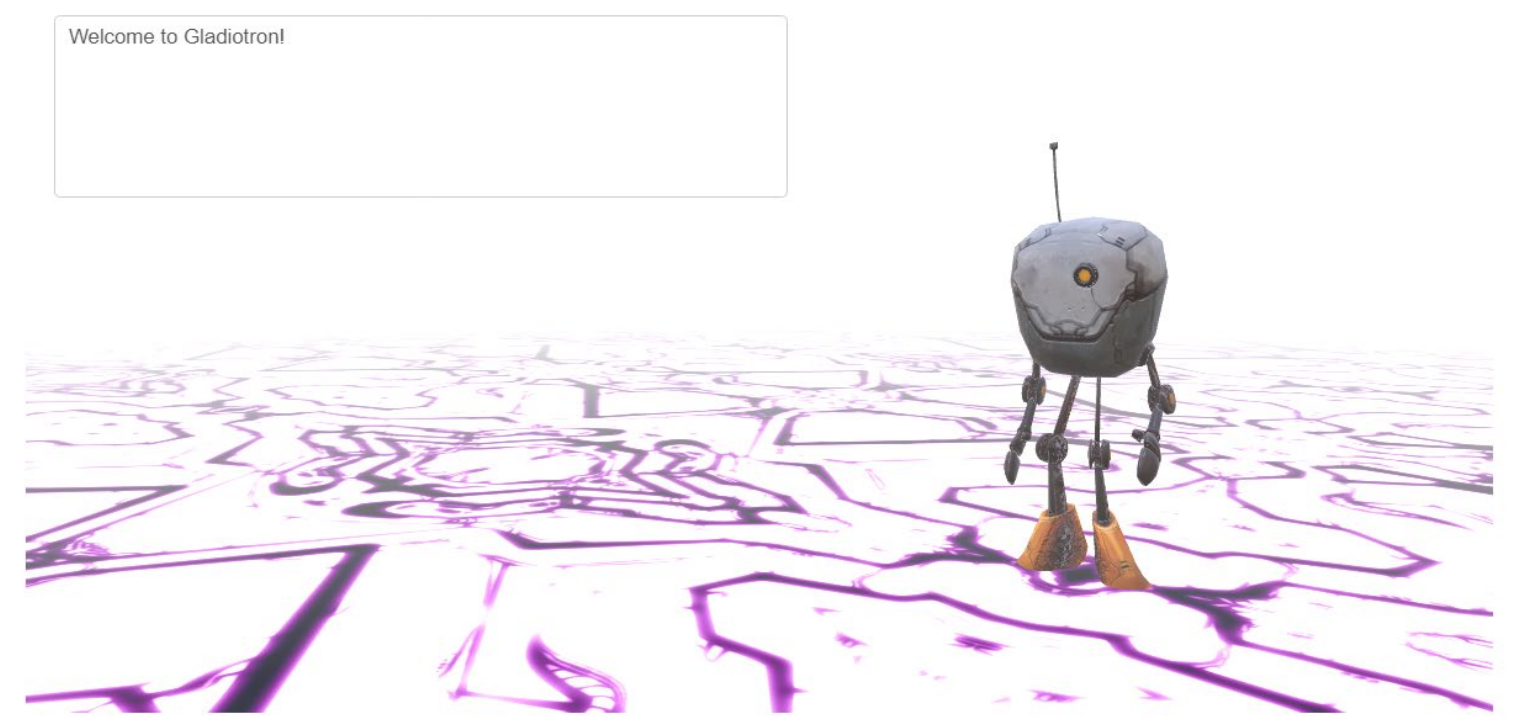

미Post a comment

Figure 20 - First page of the 3D web-comic

Getting characters and scenes quickly from Blender (Figure 21) to the website (Figure 22) has been an important component of the development process. In recent tests, this process performs flawlessley with the exception of having to add a few lines of code into the Babylon.js scripts to adjust the transparency on the characters outer eye geometry, which should render as clear and glossy. Currently it exports from Blender as opaque, which makes it impossible to see the characters eyes as it has been set up. The changes to the code fixes this issue. The code will need to be included in every script where the character appears in order to have it render properly. 


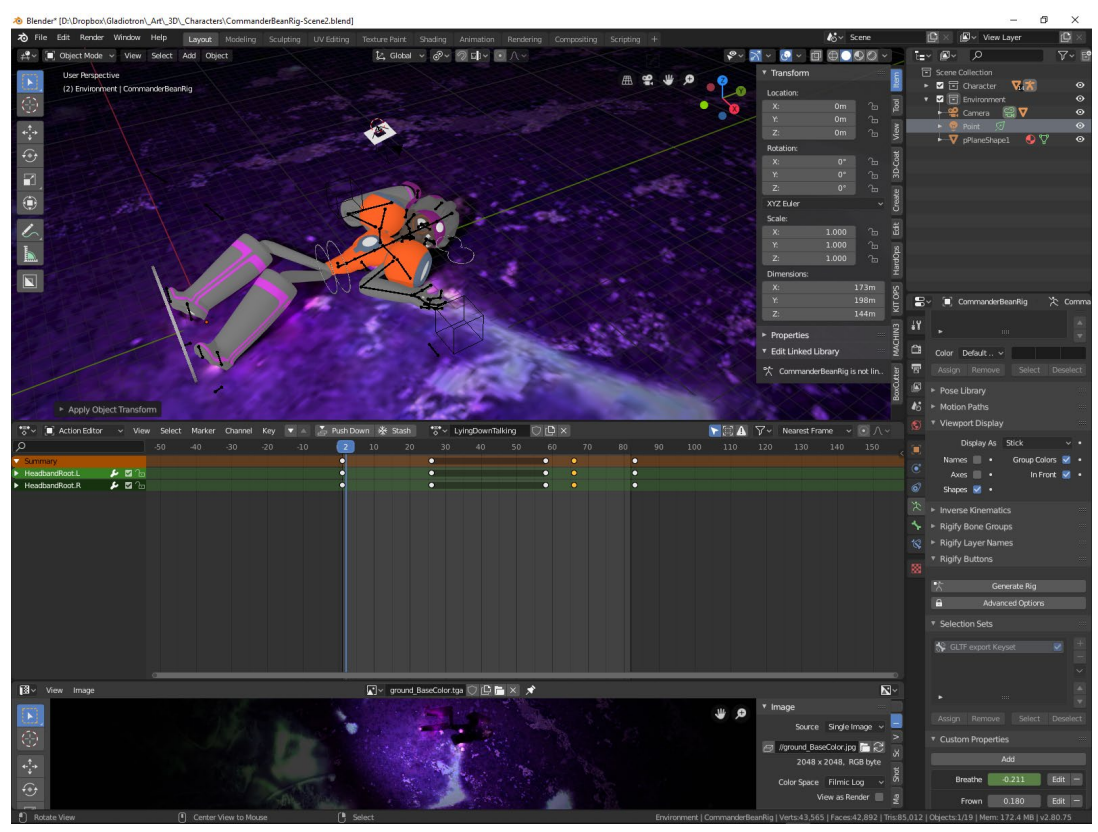

Figure 21 - Scene from one of the panels shown in Blender
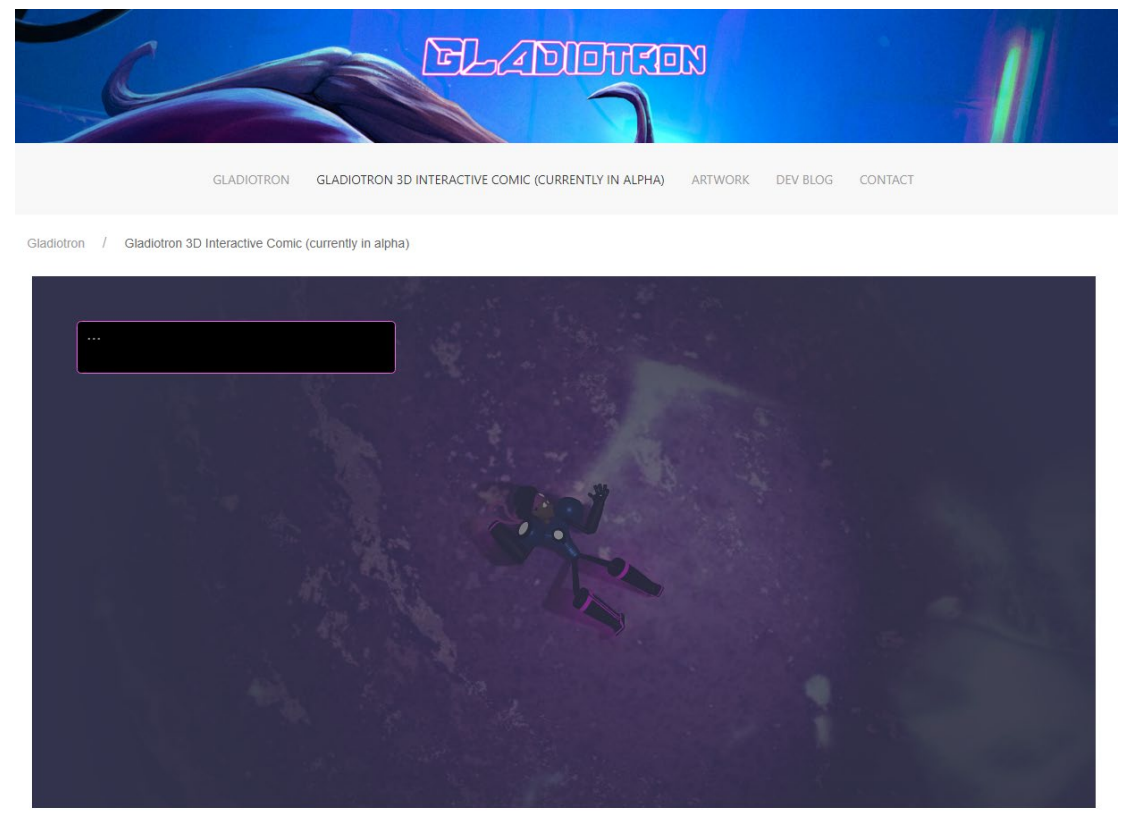

$\square$ Post a comment

Figure 22 - Panel as seen on the website

The design principles for the comic have yet to be fully integrated. And will be gradually rolled out over the course of the next few weeks in additon to story content updates. 


\section{Results \& Outcomes}

\subsection{Speed}

The web platform has been created and is fully functional. Estimates have been determined in terms of iteration speed and time to create new panels. Some things still require testing as the comic is still in its alpha stage of development as of this writing. The assets transfer seamlessly from Blender to 3D web-comic and from Blender to game with no issues aside from the slow glb and gITF Blender export times as mention earlier. While this is a nuisance, it is still a much faster process than having to redraw characters and scenes as would be the case in traditional 2D comics. The equivalent 2D artwork would take our team a minimum of 2 hours per panel as opposed to one new panel every 10 to 30 minutes using $3 \mathrm{D}$ assets. This takes into account the slow glb/glTF exports from Blender.

\subsection{Website User Testing}

Three user testing sessions have been conducted to date with people who had no prior experience with the project. These were done at various stages during the development of the website.

The first test was done when the webpage only had placeholder art and one 3D panel with a test scene that had an animated robot and music playing. The robot was positioned far away from camera and there was a great deal of white fog in the scene, so the robot was hard to perceive, and the 3D panel was set on a white background. This was done intentionally to make the border of the 3D panel invisible so that the robot would look like it was in the web page. User feedback received at this stage was primarily related to the overall aesthetics of the site, 
with feedback stating that it looked 'simple' and the users did not know what the project was about. The feedback on the 3D panel was that it was cool, but the controls were not intuitive and the robot character was so faint, they didn't realize it was there. This led to an overhaul of the website to get it looking more modern. This was achieved by using a full-screen splash art image from Gladiotron as the landing page, along with a scroll effect and a dynamic menu bar that fades out when scrolling down and pops back in when scrolling up. For the 3D test scene, a text box was added within the borders of the 3D panel to provide some instructions for the user. The camera was also repositioned so that the robot was more prominent in frame to be clearly visible and not obscured by fog. One additional page was added to the $3 \mathrm{D}$ web-comic to serve as the start of the story. The 3D test scene with the robot was now being used as an introduction to the $3 \mathrm{D}$ experience.

At the second user testing session the feedback was positive in terms of the aesthetics of the site, but there was still confusion regarding the project. The instructions on the introductory 3D panel were not read and users described the experience as being more like a game than a comic. In response to this feedback, the text block was made dynamic so that users could single click to reveal a new line of text. This was done in order to present the text in smaller chunks. Also, more comic pages were added so that the users could double click on a panel to get to the next page. Three 3D panels in total were added, with each panel having text that changed with a single mouse click (or finger tap on touch enable devices).

At the third user testing session, feedback was again positive overall. There were less comments on the website and more comments on the 3D web-comic. The music was well received aside from the third panel where the music was described as inappropriate. The visuals and animations were well received also. In response to this round of feedback, the song for the 
third page was changed to something more appropriate. And in response to prior feedback, the site was revisited with new copy that is more descriptive of the project in order to answer questions users were having about what the project was. A new 3D panel was included on the main page that depicts a fictionalized videogame cartridge from the time period of the game. This was added to provide users with an initial interaction with a 3D panel prior to them reading the $3 \mathrm{D}$ web-comic.

The project has since been shared publicly on Facebook and Instagram for user feedback. Feedback was provided through comments and has been since been addressed wherever possible. The feedback provided was for relatively minor issues, but ranged from suggestions about the website, to the interface, to the texture resolution in one of the scenes.

The project is currently in a good position to begin soliciting even more feedback from users both online and in person at user testing events that are planned. So far iterating on changes has been a very quick process. Content updates will soon begin on a regular schedule.

\subsection{Additional Outcomes}

Creating the comic webpage has had the added benefit of creating a framework that can be repurposed for future projects we create and it has also resulted in a website that will be the home to all things Gladiotron, including an about section, a shop, a blog and a section for game updates. 


\section{Conclusion}

Overall, the process of creating a 3D interactive web-comic has been somewhat arduous, but that is largely due to the newness of it to this development team. Greater familiarity with the inner workings of content management systems and the languages associate with the WebGL API such as Babylon.js, Three.js and JavaScript, would likely have resulted in a much smoother website development process. That being said, once the time-consuming part of setting up the environment was completed, the process of updating and adding new panels was extremely fast, very modular, highly extensible, and easy to iterate upon. This paper represents the beginning of this process and having reached this point our team looks forward to sharing Gladioron webcomic content updates on a regular basis while making timely adjustments based on user feedback.

\subsection{Benefits}

This process represents an opportunity to introduce an innovative approach to making comics, and as such there is a great deal of potential for growth and development. The speed of user feedback to update in the comic can be as fast a as a few minutes if the change is simple like changing dialog or adjusting the camera viewpoint. Changing character poses or animations is also quite fast and it would be feasible to make a brand-new scene in ten to fifteen minutes once the assets have been prepared. Merchandise is relatively simple to generate as poses can easily be converted to $3 \mathrm{D}$ print ready geometry or rendered out as images for posters. Most importantly, the library of assets created can greatly speed up the development of an associated game or animation project. 


\subsection{Challenges}

While this method is useful in some scenarios, it is not for everyone. There is significantly more prep time required to create the assets. Also, once made 3D assets can be somewhat rigid in terms of the ways they can be presented when compared to drawings. For example, it would be trivial for a skilled artist to invent complex and exaggerated facial expressions on a character, whereas a 3D character can only be posed in the ways that it has been designed to. Also, a higher degree of technical skill is required by the creator of a $3 \mathrm{D}$ web-comic than a traditional comic book artist would generally possess. Normally, traditional artists do not need to know anything about programming, rigging, animation, or music, they would for a 3D interactive comic such as Gladiotron. There is also more troubleshooting required which can slow down production. Also, if a lot of new assets or characters are needed for a particular scene, it is possible that a production schedule could get delayed and regular updates could be missed.

Overall, this is a process that would be ideal for indie developers who have the requisite skills within their team. Also, the art made for the comic should be stylistically similar to what they are doing in the game so that assets could be transferred. 3D web-comics could also be good for interactive artists and storytellers looking for a new way to share their stories online.

\section{Contribution to Professional Practice}

Through the creation of an online framework that allows for the easy updating of interactive content, Gladiotron serves as a test case for an extensible platform that brings a new dimension to the online serialized comic medium. One that pulls together existing technologies in a unique way, while at the same time streamlining the indie game developer's ability to 
market their games with a comic, simultaneously beginning to engage with fans of the IP, and preparing assets for the game itself. Some of the process has been documented on the Gladiation development blog where different aspects of the development that has gone into this project are discussed such as asset preparation, planning, game development in Unreal and working with web technologies to create a 3D web-comic. This paper should serve primarily as a case study outlining the technical challenges, outcomes and benefits related to taking serialized online comics which are typically a flat 2D medium and implementing 3D game ready assets into a framework that sits somewhere at the intersection of comics and games. All this, in service of introducing a new transmedia IP to market. This project extends far beyond the scope of this paper and as such, this research can be built upon. This process will continue as the project is now ready for public facing weekly content updates to the story while tweaking the overall format. The development blog will see regular updates relaying new findings and developments during the process and should serve as a source of insight into the process we have undertaken. Important content and updates will be found on the Gladiotron website - www.gladiotron.com. If this process works out to the benefit of the project, it will likely be duplicated in future transmedia IP projects that we develop, with a more optimized process based on our findings while working on Gladiotron. If this development process does prove beneficial to Gladiotron, the process is replicable, and other teams looking to introduce their IPs to market can follow a similar process.

\section{Recommendations \& Next Steps}

Currently missing is an easy to use platform for 3D artists and game developers to create and centralize interactive 3D content. There is a company called Sketchfab that is well 
positioned to go in this direction if they choose to because they already have a large community of 3D artists and animators sharing work on their platform. However, Sketchfab limits the amount of control creators have over how their content is presented and interacted with on the site. Interaction is largely limited to moving the camera and game-like interactions are not possible. Ideally, a Webtoons style site should be could be created that caters specifically to $3 \mathrm{D}$ content using a WebGL library such as Babylon.js or Three.js.

For marketing purposes, Gladiotron's animated story content could also be put on Sketchfab with a link pointing to the actual Gladiotron website in order to attract a larger audience from people already looking for that type of media on the Sketchfab platform. A Sketchfab version of the comic would require some concessions due to the limited nature of Sketchfab's interactivity. Along the same lines, it would be possible to also create a 2D version of the comic that uses a series of still frame renders of the 3D comic to put onto a site like www.webtoons.com ("WEBTOON," n.d.) in order tap into the vibrant manhwa community that exists there. In addition to increasing audience touch points, the goal is to complete the 32-page Gladiotron comic over the course of several weeks while continually updating and preparing the Gladiotron game for a Kickstarter campaign. Community outreach will continue online as well as at game and comic tradeshows in order to continue to solicit feedback and build awareness around the project. Focus testing will be done with people in our target demographic, adolescent male and females audience and adolescent Black males in particular to ensure that the characters and story resonates with them. It is important that their day to day struggles can be conveyed through the game so that the Gladiotron characters can be shown addressing those issues in healthy ways. 
In terms of the comic platform that has been created, there is the possibility of extending it into something larger that could adapted to serve as a hub where other 3D artists or game developers who are interested in creating 3D-interactive comics could host their content as well. This would require further streamlining the $3 \mathrm{D}$ web-comic development process by making the system more modular and exploring other technologies such as Node.js for backend development and React for front end development to create a complete JavaScript solution.

Assets made for the comic will continue to be deployed for use in the game during the games ongoing development. Additional assets will also need to be created for both future chapters of the comic and for the game. Character assets for the 3D web-comic and game are currently in varying stages of development, with the Commander Bean game ready model and rig finished, Sergeant Sprout sculpted and ready for retopology and mesh optimization, Zoot at the same stage and Goom in the early stages of sculpting (Figure 23).

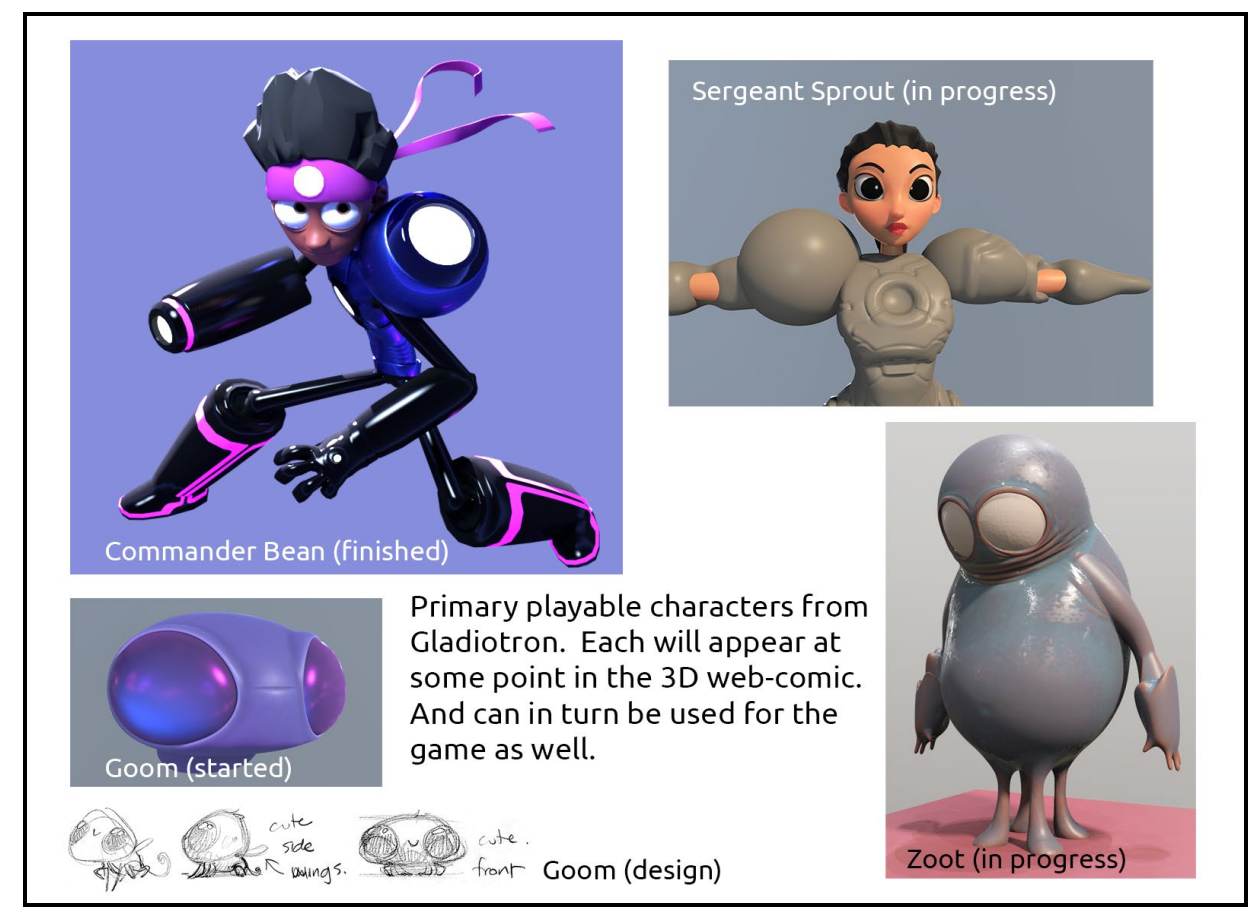

Figure 23 - Main playable characters for Gladiotron (currently in various stages of development) 
While developing the game, the efficacy of using a 3D comic as a means of marketing the game will be continually assessed to determine whether or not it is better than just doing social media alone. Additionally, the speed of game asset preparation will also be assessed to determine whether or not creating assets beforehand for the purposes of the 3D web-comic does in fact continue to yield time savings when compared to preparing assets for use in the game from scratch.

A bigger marketing push is planned and tradeshow booths at CTN Expo in Los Angeles and EGLX in Toronto have been booked in the coming months to help bring greater exposure to the project. Additional workshops and user testing sessions are being planned in Toronto, Pickering, Ajax, Whitby, and Oshawa through schools, community centres, and after school programs to help to bring awareness to the project locally. Two flyers have also been developed to this end in order to help promote the 3D web-comic and help generate social media awareness through in person engagement (Figure 24). The flyers will be used at pop up events where free caricatures that are adorned with the Gladiotron social media handles will be given to people for trying out the project. 

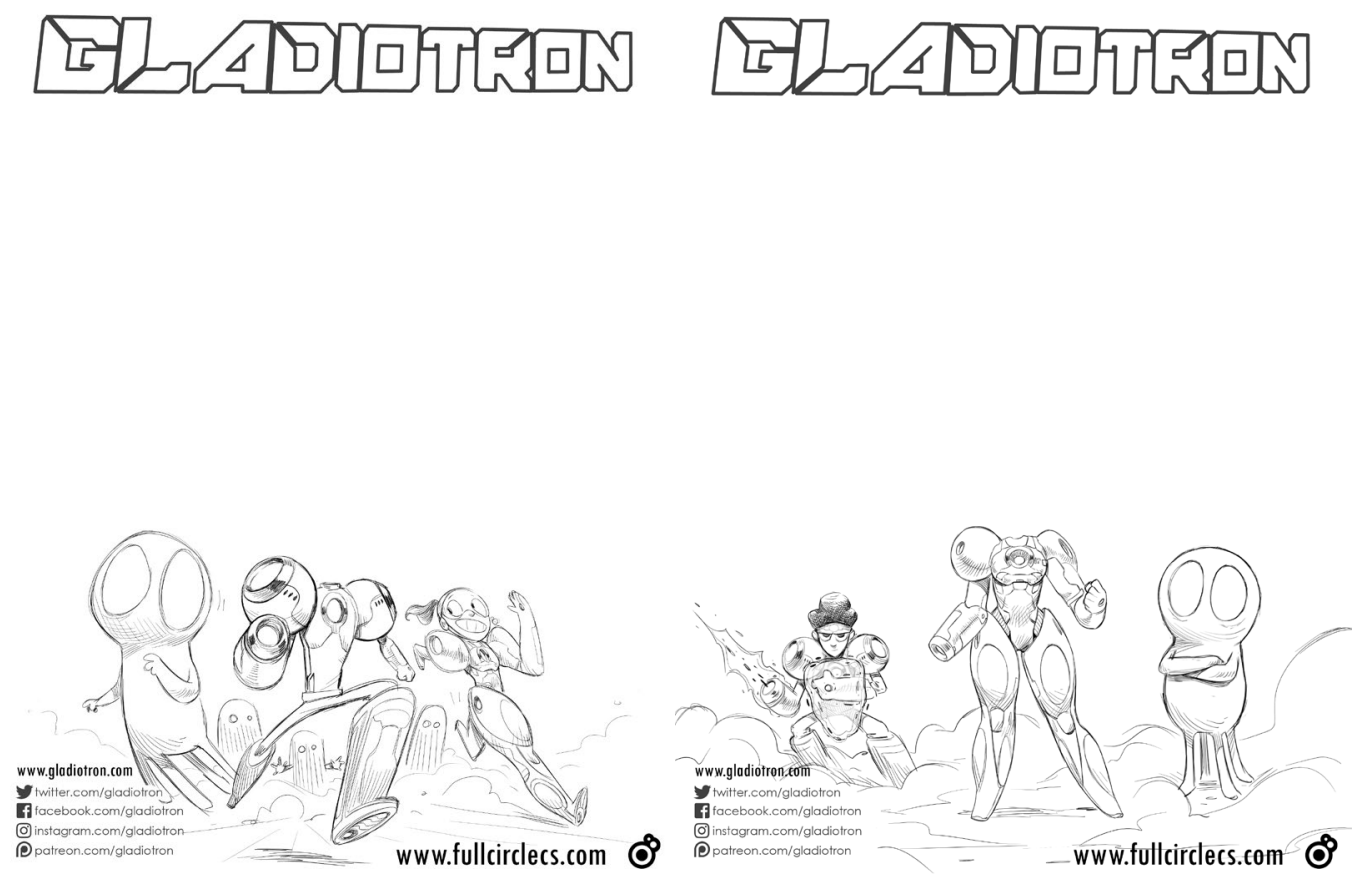

Figure 24 - Gladiotron marketing materials

A crowdfunding campaign is also planned for when the game has reached a stage where it can be demonstrated effectively. We anticipate that the marketing both on social media and through the 3D web-comic will help to bolster the crowdfunding campaign in its early stages and that early support will propel the project to greater visibility on the crowdfunding platform that is chosen (likely Kickstarter).

Finally, the hope is that by doing user testing for Gladiotron with Black male youth, this project and the team creating it will foster in them a belief that they can overcome obstacles they face and for those so inclined, become media creators as well. 


\section{Final Thoughts}

This process has been exciting and transformational. Using a comic to market an indie game always seemed like a good idea. However, lack of time has been a recurring theme and developing a comic would be time taken away from developing the game. Creating a 3D comic, however, has allowed me to serve both purposes without duplicating work. It is not a process that every team would be interested in, but for those who have the skills to make a game using 3D assets, this approach would likely be possible for them as it requires all the same skills as game development would and allows for several benefits not available through traditional methods of production. 


\section{References}

Aarsand, P. A. (2007). Computer and video games in family life: The digital divide as a resource in intergenerational interactions. Childhood, 14(2), 235-256.

Abad, J. C. (2018). Soaked girl Heikala Tribute [3D model]. https://sketchfab.com/models/fac6228f16354adeb1c18636dd9cf33f

Bąk A., Wojciechowska M. (2019) Using the Game Engine in the Animation Production Process. In: Huk M., Maleszka M., Szczerbicki E. (eds) Intelligent Information and Database Systems: Recent Developments. ACIIDS 2019. Studies in Computational Intelligence, vol 830. Springer, Cham

Bergen, J. (2017, July 24). The Rocky Journey of Hiveswap's Development. Retrieved August 22, 2019, from Cultured Vultures website: https://culturedvultures.com/rocky-journeyhiveswaps-development/

Bestebroer, P. (2017, August 9). Stop being a stupid indie-gamedeveloper. Retrieved August 29, 2019 , from https://gamasutra.com/blogs/PascalBestebroer/20170809/303382/Stop being a stupid indiegam edeveloper.php

Brubaker, J. (2011). Growing Your Audience. Retrieved from http://www.remindblog.com/2011/08/30/growing-your-audience/

Character Blogs-Hope. (n.d.). Retrieved June 1, 2019, from Center for Scholars and Storytellers website: https://www.scholarsandstorytellers.com/character-blogs-hope

Chatterjee, A. (2019, August 11). What Is Shounen Manga? [Meaning, Definition]. Retrieved August 18, 2019, from OtakuKart News website: https://news.otakukart.com/300811/what-isshounen-manga-meaning-definition/ 
Cicchirillo V, Appiah O. The impact of racial representations in video game contexts:

Identification with $\quad$ Gaming Characters. New Media Mass Commun. 2014;26:14-21. doi:10.7176/NMMC.vol2614-21.

Get Wright On It. (2017, February 23). Animation Price Guide and 3D VFX Cost Calculator [Company]. Retrieved August 15, 2019, from Get Wright On It website: https://getwrightonit.com/animation-price-guide/

Diehl, H. (2018, December). IBISWorld industry report 51121e: Video Game Software Publishing in the US. Retrieved from IBISWorld database.

Eui-chul, S., \& Hyun, K. J. (2019). Reid. Retrieved from https://comic.naver.com/webtoon/detail.nhn?titleld=729039\&no=10\&weekday=mon

Eisenbeis, R. (2014). A History of Shonen Jump Crossover Games. Retrieved August 18, 2019, from Kotaku website: https://kotaku.com/a-history-of-shonen-jump-crossover-games$\underline{1555150120}$

Failes. (2017, September 12). Upcoming Animated Series “Zafari” Is Being Rendered Completely With The Unreal Game Engine. Retrieved August 22, 2019, from Cartoon Brew website: https://www.cartoonbrew.com/tools/upcoming-animated-series-zafari-renderedcompletely-unreal-game-engine-153123.html

Francis, B. (2019). The imperfect science of Falcon Age 's baby bird-based social media marketing. Retrieved August 19, 2019, from Lview/news/340980/The imperfect science of Falcon Ages baby birdbased social media mark eting.php

Frank, A. (2017, August 29). Five years later, Homestuck game Hiveswap is finally coming out. Retrieved August 22, 2019, from Polygon website: 
https://www.polygon.com/2017/8/29/16222146/hiveswap-release-date-trailer-homestuckadventure-game

Gilbert, B. (2016). Disney just shut down a huge project that was supposed to be worth billions-Insiders reveal what went wrong. Retrieved August 19, 2019, from Business Insider website: https://www.businessinsider.com/inside-disneys-messy-video-game-business$\underline{2016-5}$

GITF - Runtime 3D Asset Delivery. (2013, April 3). Retrieved August 15, 2019, from The Khronos Group website: https://www.khronos.org/gltf/

HTML5 Game Devs. (n.d.). Babylon.js. Retrieved August 19, 2019, from HTML5 Game Devs Forum website: http://www.html5gamedevs.com/forum/16-babylonjs/

Hussie, A. (2018). Homestuck Official| Webcomics by Andrew Hussie (online). Retrieved from https://www.homestuck.com/

Japan Deluxe Tours. (2016, June 20). Comparing Cultures: Manga vs Comic Books [Blog]. Retrieved August 18, 2019, from https://japandeluxetours.com/blog/comics-vs-mangas

Jin, D. Y. (2015). Digital convergence of Korea's webtoons: Transmedia storytelling. Communication Research and Practice, 1(3), 193-209. https://doi.org/10.1080/22041451.2015.1079150

Kickstarter. (2012). Homestuck Adventure Game. Retrieved August 21, 2019, from Kickstarter website: https://www.kickstarter.com/projects/14293468/homestuck-adventure-game

Kickstarter. (2014). UnderTale by Toby Fox. Retrieved August 15, 2019, from https://www.kickstarter.com/projects/1002143342/undertale/posts

Kickstarter. (n.d.). Plans \& Pricing. Retrieved August 19, 2019, from Sketchfab website: https://sketchfab.com/plans 
Larx Entertainment \& Netflix (Producers).(2019). Kengan Ashura. [Television Series]. USA: Netflix Worldwide.

Manifesto for Agile Software Development. (n.d.). Retrieved August 15, 2019, from https://agilemanifesto.org/

Naver Webtoon. (n.d.). Retrieved August 15, 2019, from https://comic.naver.com/index.nhn

Nielsen, J. (2016). Games User Research: What's Different? Retrieved August 19, 2019, from Nielsen Norman Group website: https://www.nngroup.com/articles/game-user-research/

NPD. (2017, October 6). Comics and Graphic Novels One of Highest Growth Categories in Publishing. Retrieved from https://www.npd.com/wps/portal/npd/us/news/pressreleases/2017/comics-and-graphic-novels-one-of-highest-growth-categories-in-publishingreports-npd/

NDP. (2019, June 3). NPD BookScan: Sales of Manga Books are On the Rise in the United States. Retrieved August 18, 2019, from https://www.npd.com/wps/portal/npd/us/news/pressreleases/2019/sales-of-manga-books-are-on-the-rise-in-the-united-states-the-npd-group-says/

Prestin, A. (2013). The Pursuit of Hopefulness: Operationalizing Hope in Entertainment Media Narratives. Media Psychology, 16(3), 318-346. https://doi.org/10.1080/15213269.2013.773494

Rehkopf, M. (n.d.). Sprints. Retrieved August 19, 2019, from Atlassian website: https://www.atlassian.com/agile/scrum/sprints

Shogakukan Inc. (2019). ULTIMATE BATTLE (Version 1.0.7) [Android]. Retrieved from https://apps.qoo-app.com/en/app/7256

Superannuation. (2014, January 15). How Much Does It Cost To Make A Big Video Game? Retrieved August 15, 2019, from Kotaku website: https://kotaku.com/how-much-does-it-costto-make-a-big-video-game-1501413649 
Terdiman, D. (2014). No, Flappy Bird developer didn’t give up on $\$ 50,000$ a day. Retrieved August 18, 2019, from CNET website: https://www.cnet.com/news/no-flappy-bird-developerdidnt-give-up-on-50000-a-day/

Verge3D. (2019, May 30). Comparing Unity, Sketchfab and Verge3D [Company] Retrieved August 19, 2019, from Soft8Soft website: https://www.soft8soft.com/comparing-unitysketchfab-and-verge3d/

Waters, K. (2007, June 10). 10 Good Reasons To Do Agile Development. Retrieved August 19, 2019, from 101 Ways website: https://www.101ways.com/2007/06/11/10-good-reasons-to-doagile-development/

WebGL - OpenGL ES for the Web. (2011, July 19). Retrieved August 14, 2019, from The Khronos Group website: https://www.khronos.org/webgl/

Quora. (n.d.). Why did your indie game fail? Retrieved August 14, 2019, from https://www.quora.com/Why-did-your-indie-game-fail

Zafari Holdings \& BE3 Animation (Producers). (2018). Zafari [Television series]. USA: NBC Worldwide. 